\title{
Forecasting Foreign Exchange Rate and Consumer Price Index with Arima Model: the Case of Turkey
}

\author{
Abraham Deka ${ }^{1}$, Nil Gunsel Resatoglu ${ }^{2}$ \\ ${ }^{1}$ Banking and Finance Department, Faculty of Economics and Administrative Sciences, \\ Near East University, Nicosia, Turkish Republic of North Cyprus \\ ${ }^{2}$ Banking and Finance Department, Faculty of Economics and Administrative Sciences, \\ Near East University, Nicosia, Turkish Republic of Northern Cyprus
}

\begin{abstract}
The high and increasing rate of uncertainty in the world's Foreign Exchange Market (FEM) is one that poses a great concern to the market players, traders and policy makers. There is need to come up with reliable and sophisticated models of forecasting foreign exchange rate and its determinants in order to predict their future values hence reduce the risks. This paper makes use of the Autoregressive Integrated Moving Average (ARIMA) model to forecast the foreign exchange rate of Turkey and inflation a major determinant of foreign exchange rate. This paper provides that ARIMA $(3,1,3)$ is the best ARIMA model for forecasting foreign exchange rate of Turkey and that $\operatorname{ARIMA}(1,1,4)$ is the best ARIMA model for forecasting Turkey's inflation (CPI). This paper also postulates that ceteris paribus the foreign exchange rate of the lira against the dollar will be stable in the future short run. However, with the passage of time the suggested model of forecasting foreign exchange rate and inflation of Turkey should always be updated with current data. ACF, PACF, AIC and BIC together with forecasting performance measures like MAE, MAPE, Bias proportion, RMSE and Theil $U$ statistics are very useful in the process of best model selection.
\end{abstract}

Key words: ARIMA; Exchange rates; first; Forecasting; CPI

JEL Classification: C01

\section{Introduction}

Due to high and increasing rate of uncertainty in the world's Foreign Exchange Market (FEM) there is need to come up with reliable and sophisticated models of forecasting financial series such as foreign exchange rate (FOREX) as well as inflation in the form of Consumer Price Index (CPI) which is one of the factors that determine Foreign Exchange Rate in the Foreign Exchange Market (FEM). Coming up with a proper forecasting model such as ARIMA in this case is essential for increasing profitability in the FEM; help investors in coming up with informed decisions on their investment actions as well as helping the government in policy making. Because of the above mentioned reasons, this paper makes use of BoxJenkins methodology, ARIMA model, to forecast Foreign Exchange Rate of the US dollar against the Turkish Lira and CPI of Turkey.

This paper seeks to study the Foreign Exchange Market of Turkey due to the 2018 currency crisis in Turkey which has resulted in the exchange rate of lira depreciating at an alarming rate against other currencies. This paper seeks to see how best the ARIMA model can help investors predict and forecast the future values of the foreign exchange rate which will in turn go a long way in reducing the risk of loss involved in FOREX trade.

ARIMA model is a model of forecasting financial time series variables such as CPI, exchange rate and share price just to mention but a few, Adhikari and Agarwal (2009) and Verenius (2017). According to Adhikari and Agarwal (2009) ARIMA model is referred to as Autoregressive Integrated Moving Average model and is a combination of Autoregressive (AR) and Moving Average (MA) models as well as the Integration 
process which is the process at which a non-stationary time series variable is differenced to make it stationary.

Box and Jenkins (1976) provides for a three step method which is very crucial in the process of selecting the best ARIMA model. These three steps are identification, estimation and diagnostics testing. These three steps can be repeated several times in order to come up with the most appropriate model (Box \& Jenkins, 1970). The principle of parsimony is very crucial in selecting the best ARIMA model as this seeks to avoid over fitting the model.

This paper provides that the best ARIMA model for forecasting TRY/USD exchange rate is ARIMA $(3,1,3)$ because it has the least values of the three forecasting performance measures of RMSE, MAE and Theil U statistic indicating that it has the lowest forecasting error size, hence we pick the one with least error size than direction, Klimberg, et al (2015). Furthermore, the best ARIMA model that can be used to forecast CPI of Turkey is ARIMA $(1,1,4)$. The results of the AIC and BIC are the same with those of the forecasting performance measures.

ARIMA model with the least forecasting performance results is the one that is the best model since it indicates that it has the minimum possible error in both size and direction and this is in line with Klimberg et al (2015) and Adhikari and Agrawal (2009). In line with Klimberg et al (2015) this paper provides that if the bias proportion is closer to zero the model is the best and in this case all models have produced very small values of bias proportion.

In addition to that, this paper concurs with Adhikari and Agrawal (2009) that ACF and PACF are the best functions that can be used for model identification which helps in coming up with tentative models that can be estimated to find the best model. ACF and PACF are also used at stage three of Box-Jenkins methodology of diagnostic testing. After running the residual diagnostic tests correlogram and the residual squared diagnostic test correlogram the $\mathrm{ACF}$ and PACF values are checked to see if they are flat and within the error bound. Therefore, this paper concludes that ACF and PACF plays a major role in coming up with the best ARIMA model otherwise a proper model cannot be obtained.

This paper also provides that holding other things constant the Turkish Lira foreign exchange rate is going to have short run stability with minor fluctuations if any.

\section{Literature Review}

\subsection{Box-Jenkins methodology and the Principle of Parsimony}

According to Waeto, Chuarkham and Intarasit (2017), the Autoregressive (AR), Moving Average (MA), Autoregressive Moving Average (ARMA) and the Autoregressive Integrated Moving Average (ARIMA) models are known as the Box-Jenkins models. Adhikari and Agrawal (2009) postulated that AR, MA and ARMA models are used for stationary time series data whereas the ARIMA model is used for non-stationary time series data which is subject to differencing in order to make it stationary. According to Adhikari and Agrawal (2009) the real time series data used in the world of business, economics and finance is generally non-stationary and should be differenced in order to make it stationary.

According to Adhikari and Agrawal (2009) the Box-Jenkins methodology follows a three step procedure in the process of coming up with the best ARIMA model for forecasting. The steps are as follows: identification of the ARIMA model, estimation of parameters and diagnostic testing. Adhikari and Agrawal (2009) argued that the three step process is repeated several times up until the best parsimonious ARIMA model is obtained. Figure 1 below summarizes the three step procedure of the Box-Jenkins methodology. 


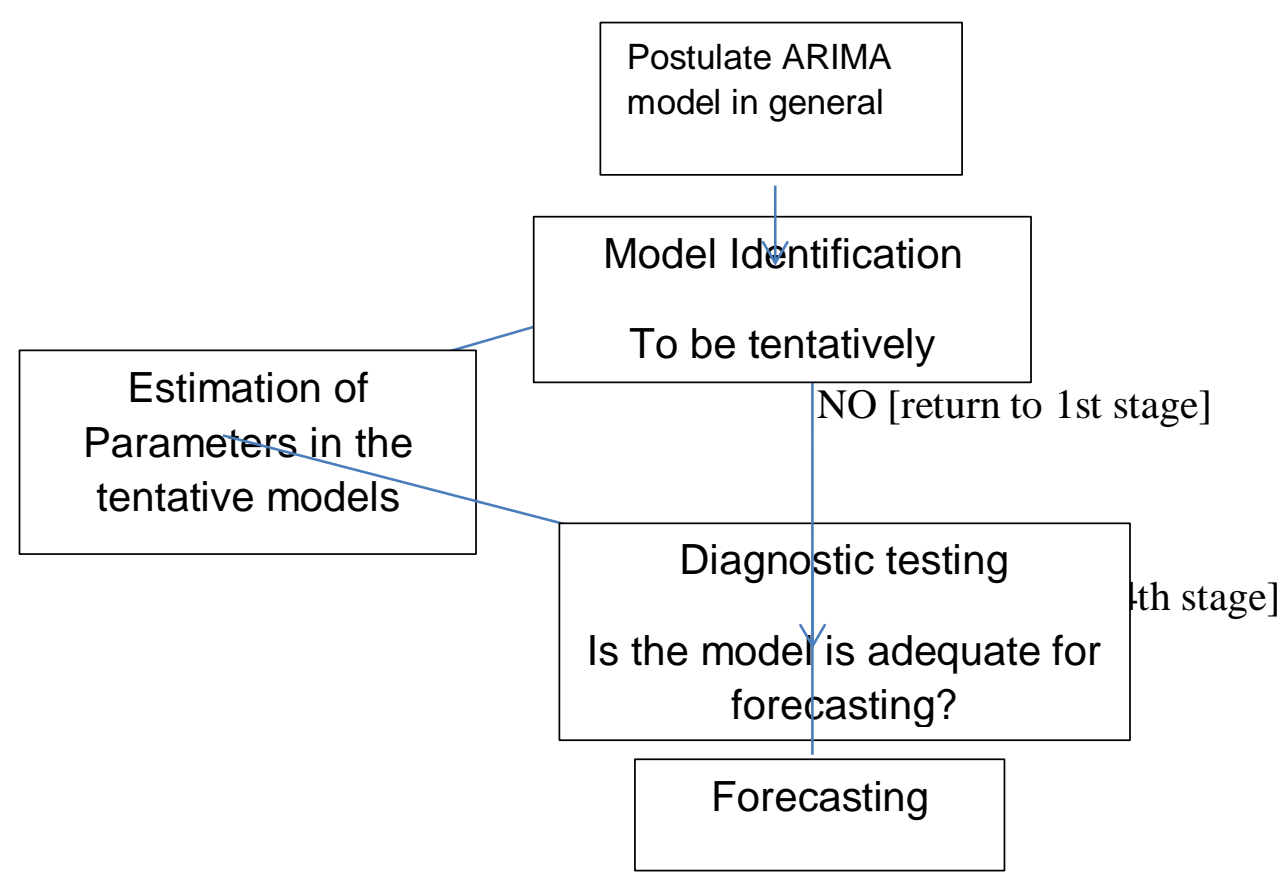

Figure 1: Box-Jenkins process of model selection Source: Adhikari and Agrawal (2009)

Chatfield (1996), Zhang (2007) and Zhang (2003) concur that the best and proper time series model is obtainable by considering the principle of parsimony in order to come up with robust forecasting results. The principle of parsimony states that the best model is one that contains the smallest possible number of parameters, Chatfield (1996), because it tend to provide a representation which is fairly adequate for the time series data. Therefore, when choosing the best ARIMA model parsimonious principle has to be put into consideration in order to come up with robust results.

Adhikari and Agrawal (2009) argue that the principle of parsimony is closely related to the Occam's razor principle as postulated in Mcleod and Hipel (1994) which suggest that, a simple model is the one that provides adequate explanation. According to Adhikari and Agrawal (2009) a complicated model has more tendencies of diverting from the model's actual assumptions. The more the parameters of a model the higher is the risk of over fitting the model (Adhikari \& Agrawal, 2009). A time series model that is over fitted tends to describe the data well at the expense of failing to suitably make future forecasting, according to Adhikari and Agrawal (2009).

\subsubsection{Autoregressive (AR) model}

According to Gujarati (2004) and Adhikari and Agrawal (2009) an Autoregressive AR(p) model is a model that predicts the future values of a time series variable by making use of the past observations values together with the error term and the constant. Therefore, it can be noted that an AR(p) model is a regression form of the dependent future value with its independent past or lag values. An Autoregressive model with 5 past lag values is represented as $\operatorname{AR}(5)$ model. Eq. 1 below shows how an $A R(p)$ model can be expressed in a mathematical form.

$Y t=c+\beta 1 Y t-1 t \beta 2 Y t-2+\ldots \ldots \ldots \ldots \ldots \ldots+\beta p Y t-p+u t$

In the equation above $Y t$ represents the future value that is to be predicted by its past lag value as represented by $\boldsymbol{Y t}-\mathbf{1}, \mathbf{Y t}-\mathbf{2}, \ldots \ldots . . ., \mathrm{Yt}-\boldsymbol{p} ; \boldsymbol{c}$ is the constant term and $\boldsymbol{e t}$ is the white noise error term and $\boldsymbol{\beta 1}, \boldsymbol{\beta 2}, \ldots . . ., \boldsymbol{\beta p}$ are parameters of the $\mathrm{AR}(\mathrm{p})$ model.

\subsubsection{Moving Average (MA) model}

Waeto et al (2017), Adhikari and Agrawal (2009) and Gujarati (2004) concur that a Moving Average MA(q) unlike the $\operatorname{AR}(p)$, makes use of the past values of its white noise error terms as its explanatory variables. The term $\boldsymbol{q}$ represents the number of past error terms used in the Moving average model and is an integer greater than 1. Therefore, a Moving Average model with 3 past error terms is illustrated as MA(3) model. Below is a mathematical illustration of a MA(q) model.

$Y t=\mu+\theta 1 \varepsilon t-1+\theta 2 \varepsilon t-2+\ldots \ldots \ldots \ldots . . .+\theta q \varepsilon t-q+\varepsilon t$ 
In the Eq. 2 above $\boldsymbol{\mu}$ represents the mean value of the series, whereas $\boldsymbol{\theta 1}, \boldsymbol{\theta 2}, \ldots . ., \boldsymbol{\theta q}$ are the parameters of the model and $\mathrm{q}$ is the model order, Adhikari and Agrawal (2009).

\subsubsection{Autoregressive Moving Average (ARMA) model}

An ARMA(p,q) model according to Adhikari and Agarwal (2009) is a model that is derived by combining the Autoregressive AR(p) model, illustrated in Eq. 1 in the section above and the Moving Average MA(q) model, illustrated in Eq. 2 in the section above. It is suitable for analyzing univariate time series. Combining Eq. 1 and Eq. 2 will arrive at ARMA (p, q) model which has its explanatory variables being both the lag values of $\mathrm{Yt}$ and the lag values of the error term of $\mathrm{Yt}$ as illustrated in Eq. 3 below.

$\boldsymbol{Y t}=\boldsymbol{c}+\boldsymbol{\beta} 1 Y t-1 \boldsymbol{t} \boldsymbol{\beta} 2 Y t-2+\ldots .+\beta p Y t-p+\theta 1 \varepsilon t-1+\theta 2 \varepsilon t-2+\ldots . .+\theta q \varepsilon t-q+\varepsilon t$

Adhikari and Agrawal (2009) and Waeto et al (2017) argued that ARMA(p,q) model is just but a theoretical model which is only used for stationary time series variables. Adhikari and Agrawal (2009) argues that most variables in socio-economic and business are non-stationary hence the $\operatorname{ARMA}(p, q)$ model has to be generalized into an $\operatorname{ARIMA}(p, d, q)$ which caters for the integral process of differencing a non-stationary process to become stationary.

\subsubsection{Autoregressive Integrated Moving Average (ARIMA) model}

According to Waeto et al (2017) citing Box and Jenkins (1976), an Autoregressive Integrated Moving Average model is a generalization of an Autoregressive Moving Average model to forecast non-stationary time series process that is made stationary through a difference stationary process or integrated process in order to make it stationary. Thus Waeto et al (2017) argued that by adding $\boldsymbol{d}$ times differencing on the stationary $\operatorname{ARMA}(p, q)$ we obtain $\operatorname{ARIMA}(p, d, q)$ model. Thus it can be said that $\mathrm{d}$ represents the number of times a non-stationary time series has been differenced in order to make it stationary and normally it is only once $(\mathrm{d}=1)$ especially for time series with a unit root, Gujarati, 2004 and Adhikari and Agrawal (2009).

$$
\Delta d \mathrm{Y} t=\mathrm{c}+\beta 1 \Delta d \mathrm{Y} t-1+\cdots+\beta p \Delta d \mathrm{Y} t-p+\beta 1 \mathrm{e} t-1+\cdots+\beta q \mathrm{e} t-q+\mathrm{e} t
$$

The Eq. 4 above represents the time series that has been differenced $\boldsymbol{d}$ times. $\Delta d$ is the $d t h$ time at which the time series has been differenced. Adhikari and Agrawal (2009) postulates that ARIMA models make use of non-stationary time series variables that are subject to finite differencing in order to make them stationary. Waeto et al (2017) and Adhikari and Agarawal (2009) concurs that the mathematical formulation of an ARIMA model is given as $\operatorname{ARIMA}(p, d, q)$, where $\mathrm{p}, \mathrm{d}$, and $\mathrm{p}$ are integers that are greater or equal to zero and they give reference of the autoregressive, integration and moving average parts respectively.

Adhikari and Agrawal (2009) argue that it is the integer d that controls the differencing level. If $d=0$ [ARIMA(p,d,q)] then automatically that ARIMA model becomes ARMA(p,q) because the time series variable is stationary without differencing it. $\operatorname{ARIMA}(0,1,0)$ according to Adhikari and Agrawal (2009) is a special type which is known as a random walk model and is widely used for non-stationary data such as stock prices and economic series.

\subsection{Autocorrelation and Partial Autocorrelation Functions}

According to Adhikari and Agrawal (2009) and Gujarati (2004), Autocorrelation Function (ACF) and Partial Autocorrelation Function (PACF) are the most widely used identification techniques of the ARIMA orders as per Box and Jenkins (1976) suggestions. Adhikari and Agrawal (2009) argue that ACF and PACF is one of the crucial criterion used in the selection process to determine the model's optimal parameters. Table 1 below gives a brief summary of how the spikes of the ACF and PACF can be used to identify the best ARIMA model.

Table 1: Identification of the best ARIMA to use

Source: Adebayo, Sivasamy and Shangodoyin (2014) and Gujarati (2004)

\begin{tabular}{|c|c|c|}
\hline Model & ACF pattern & PACF pattern \\
\hline AR(p) & Geometric decay & Significant spike of lag p \\
\hline MA(q) & Significant spike of q lag & Geometric decay \\
\hline ARMA(p,q) & Geometric decay (same pattern with & $\begin{array}{c}\text { Geometric decay (same pattern with } \\
\text { PACF) }\end{array}$ \\
\hline
\end{tabular}

The other measures used in the ARIMA selection process according to Faraway and Chatfield (1998), and Adhikari and Agrawal (2009) are the Akaike Information Criterion (AIC) and Bayesian Information Criterion (BIC). Adhikari and Agrawal (2009) argues that the best model is the one that provides the least value of AIC and BIC. 


\subsection{Forecasting Performance Measures}

According to Klimberg, Sillup, Boyle and Tavva (2015) the measures used to evaluate forecast performance are generally classified into two categories which are directional and size. Bias is considered as the primary measure that is used to evaluate the error direction of a forecast model. In order to evaluate on whether a forecasting model gives under or overestimated values from the actual ones we check bias of the forecasting model. Klimberg, Sillup, Boyle and Tavva (2015) argues that bias is the average of all forecast errors in a model and is calculated as follows; Bias $=\left[\sum(\mathbf{Y t}-\mathbf{F t})\right] / \mathbf{n}$. Adhikari and Agrawal (2009) termed the forecast bias as the Mean Forecast Error (MFE). Klimberg et al (2015) and Adhikari and Agrawal (2009) concurs that a forecast bias of zero does not mean the forecast is perfect nor does not contain any error, rather it indicates that the forecast is on the proper target. The best model should have a bias which is very small close to zero since the expected bias is zero. A positive bias indicates that the model underestimates the actual values whereas; a negative bias shows that the model overestimates the actual values.

Klimberg et al (2015) postulated that it is the size of the error that matters on the side of management due to the fact that most models are usually unbiased because they produce an expected value that is close to zero. The Mean Absolute Deviation (MAD) also known as the Mean Absolute Error (MAE) is the most popular measure of forecasting performance, Klimberg et al (2015). Wallstrom (2009) postulated that MAD is a measure of variance, while Adhikari and Agrawal (2009) define MAD as a measure of average absolute deviations of the values that has been forecasted as compared with the original values. Adhikari and Agrawal (2009) provide that MAE shows a general idea of the overall error that has occurred during forecasting. The mathematical calculation of MAD according to Klimberg et al (2015) is written as; MAD = $\left(\sum|\mathbf{Y t}-\mathbf{F t}|\right) / \mathbf{n}$. Klimberg et al (2015) concurs with Adhikari and Agrawal (2009) that the best forecasting is one with the smallest value. In as much as MAD is easy to be understandable it however lacks a strong statistical relationship compared to MSE, Wallstrom (2009).

Mean Squared Error (MSE) is a common forecasting error and variance measure, Wallstrom (2009). It is one of the performance measures that measures error size by measuring the amount of error dispersion, Klimberg et al (2015). The mathematical calculation of MSE according to Klimberg et al (2015) is as follows; MSE $=\left[\sum(\mathbf{Y t}-\mathbf{F t})\right] / \mathbf{n}$. MSE is used to measure the forecasted value's squared deviation values and error value with opposite signs does not offset each other, (Adhikari \& Agrawal, 2009). MSE penalizes for great errors that might have occurred during the process of forecasting. Just like is the case of MAD, a small MSE value is preferable. If we take the square root of the MSE we obtain what is known as Root Mean Square Error (RMSE), Klimberg et al (2015).

Mean Absolute Percentage Error (MAPE) is a widely and popularly forecasting evaluation method which tries to put into consideration the effect of actual values' magnitude, and is calculated as MAPE $=\left[\sum(\mid \mathbf{Y t}-\right.$ $\mathbf{F t}$ )/Yt $/ \mathbf{t} / \mathbf{n}$ Klimberg et al (2015). MAPE does not allow for opposite signed errors to offset each other. Wallstrom (2009) postulated that one of the shortfalls of MAPE is the low value denominator which tends to inflate percentage error thereby causing the occurrence of outliers. If the forecast is greater than the actual demand results then MAPE results in a greater error as compared to if the forecast is smaller than the demand, (Wallstrom, 2009).

The Theil's U-statistics is one other crucial forecast performance measure which is a normalized measure of the total forecast, Adhikari and Agrawal (2009). When $0 \leq \mathrm{U} \leq 1 ; \mathrm{U}=0$ then we can conclude that the forecast is a perfect fit of the actual results (Adhikari \& Agrawal, 2009). Other measures of forecast performance include the Normalized Mean Squared Error (NMSE) obtained by normalizing MSE by dividing it with the test variance, Signed Mean Squared Error (SMSE) which has same characteristics as MSE, the Sum of Squared Error (SSE) with same properties as MSE, according to Adhikari and Agrawal (2009).

\section{Methodology and data}

\subsection{Method}

There are several methods that can be used to analyze data. According to Kothari (2004), research methodology is referred to as the examination of some procedures being applied on a research study. It is the involvement of relationships and forecasting occurrences with the aim of elucidating predicaments and procedures of a research study being conducted. This paper make use of the secondary time series data that was recorded over a long period of time for Turkey's Foreign Exchange Market. Secondary data is the true data that was collected and verified about any institution or country as is in this case. 
Time series data refers to data of a variable(s) that was collected over a period of time in order to observe how the variable(s) behave (Gujarati, 2004). In this case the researcher made use of two time series sets of data, that is, Foreign Exchange Rate of Turkish Lira (TRY) against the United States Dollar (USD) as well as the major factor that determine Foreign Exchange Rate, inflation as derived from the Consumer Price Index of Turkey. These two variables Foreign Exchange Rate and its determinant CPI will go a long way in helping to fully forecast and predict the Foreign Exchange Market of Turkey which in turn will help traders and investors in making informed decisions hence increase profitability. This study will also help the government of Turkey to make sound policy in the FEM.

For analysis purposes ARIMA (Autoregressive Integrated Moving Average Model) is used. The ARIMA model has been chosen on the basis that the data to be analyzed is stochastic time series in nature and it has not been classified as independent and/or dependent variables, therefore ARIMA model will help come up with a model that is regressed against its lag values and/or lag values of its error term. ARIMA model is a very useful model of analyzing financial time series data in cases where it is difficult to find out independent variables that can be regressed against the dependent variable.

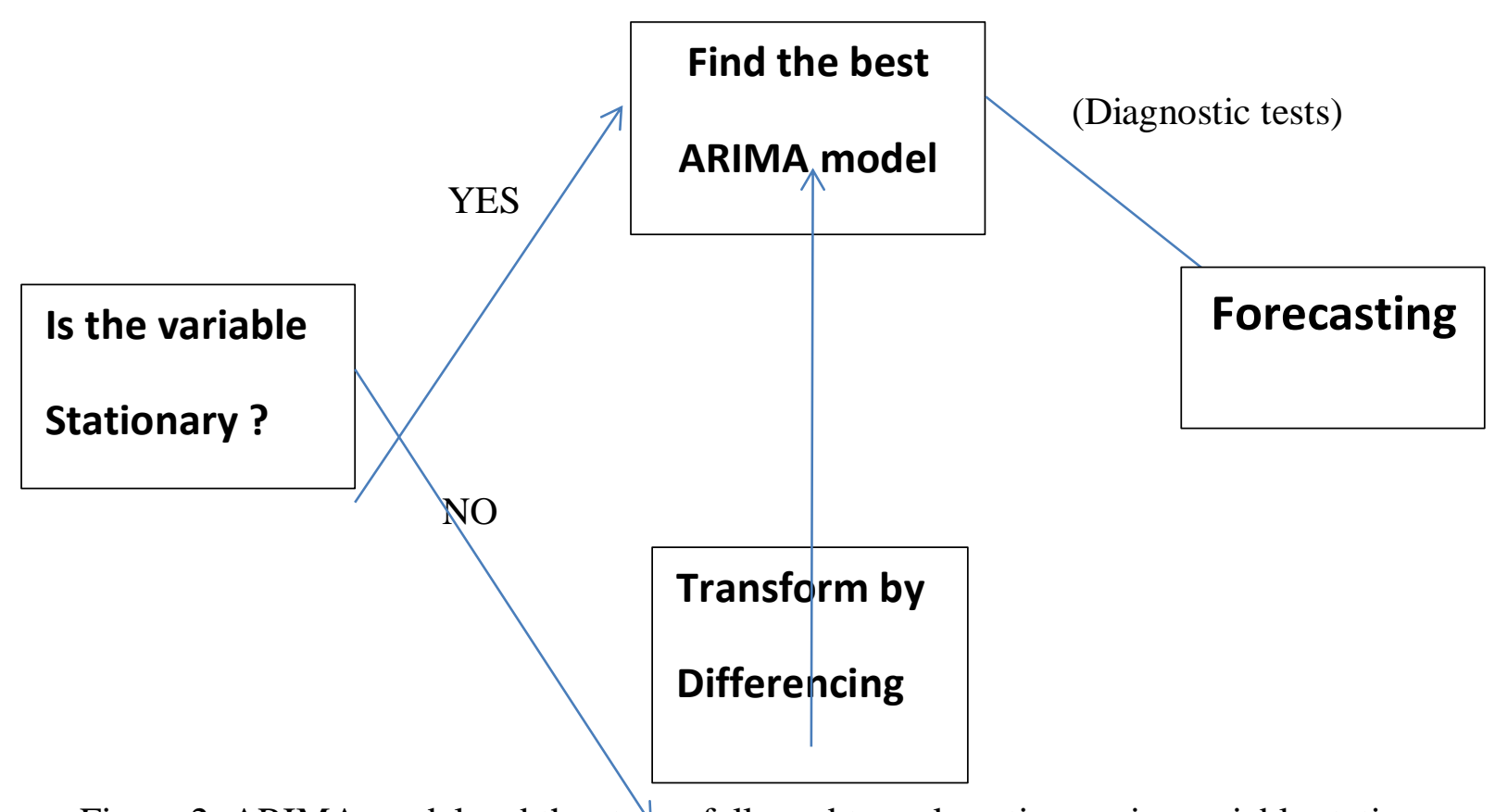

Figure 2: ARIMA model and the stages followed to make a time series variable stationary

In order to arrive at the best ARIMA model to use, the researcher is going to follow the steps as outlined in the figure above. Firstly the researcher will start by answering the question on whether the time series variables of TRY/USD exchange rate and CPI is stationary or not.

\subsection{Data description}

In this paper the researcher made use of two univariate time series variable which is Lira Exchange Rate against the dollar and the inflation of Turkey as reflected by Consumer Price Index (CPI). This paper make use of the daily exchange rate of the TRY/USD as from the $10^{\text {th }}$ of August 2018 up to the $5^{\text {th }}$ of December 2018 excluding Saturdays and Sundays since the spot exchange rate of weekends have not been accessible by the researcher. Therefore, the researcher made use of 84 daily observations of the spot exchange rate during the period mentioned above. The data of the lira exchange rate against US dollar was retrieved from www.poundsterlinglive.com . Turkey's monthly CPI (inflation) data from February 2004 up to August 2018 was also collected from www.oecd.org thus giving us a total of 175 observations. 
Gujarati (2004) and Adhikari and Agrawal (2014) concurs that before doing any diagnostic tests one has to check the way how the variable behaves by plotting the variable on the graph. Thus the graphical presentation of the variable help observe the nature of the variable. From the graphical presentation one can observe if the variable is stationary or non-stationary as well as finding out if the variable is seasonal or not and whether it contains a trend and residual or not. Pradhan et al (2016) provides for explicitly modeling of a time series data that is periodical and/or has a trend.

\section{TRY/USD}

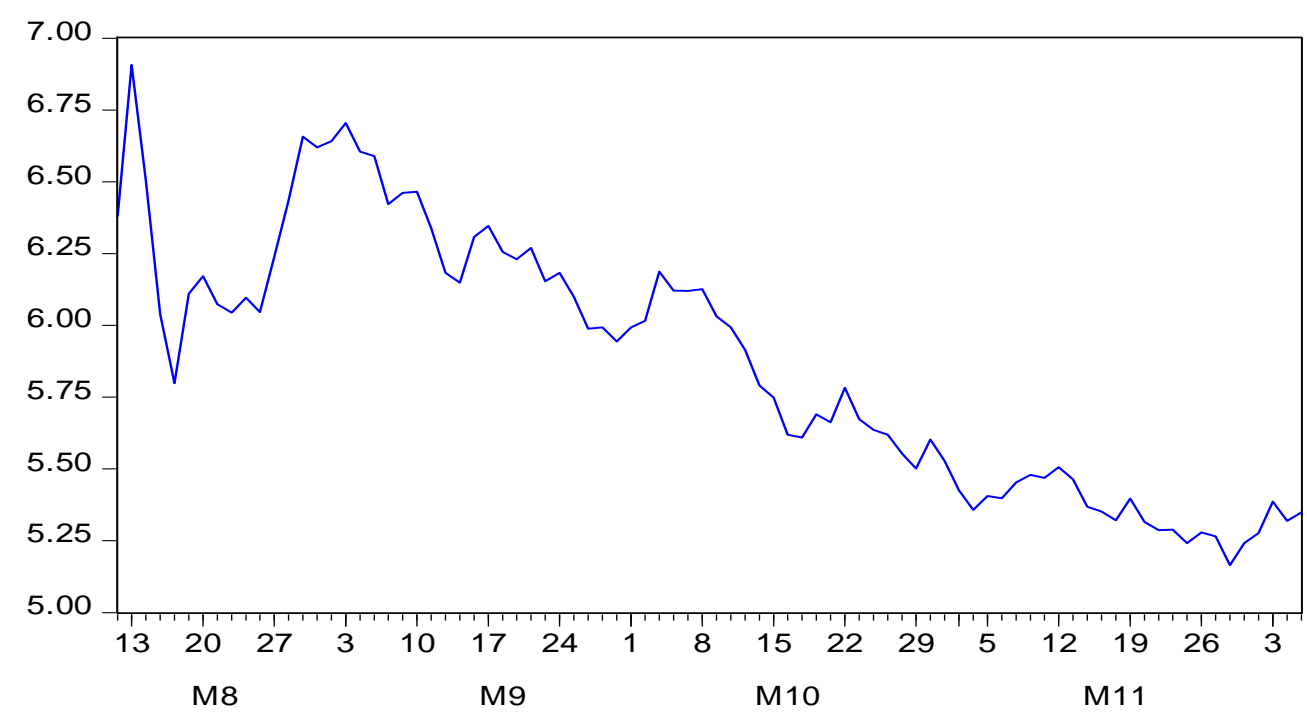

Figure 3: Graph of Turkish lira foreign exchange rate against the US dollar Source: Author's own illustration

Fig 3 above shows a graphical presentation of the daily TRY/USD exchange rate as from August 10, 2018 till December 5, 2018. In this paper the graph above shows that the graph does not start from zero on its horizontal axis, therefore when running this variable on Eviews a constant term has to be included. Furthermore, the variable is not stationary because it has got a trend and it's a stochastic trend hence it can be made stationary by differencing it. The lira's exchange rate against the US dollar thus shall be checked for unit root by ADF and Phillips Perron unit root test run with the inclusion of intercept and a trend. A difference stationary process (DSP) will also be followed to make TRY/USD stationary.

Fig 4 below shows the graph of CPI (inflation) of Turkey. From the below graph this paper shows that the graph does not start from zero meaning that it contains an intercept hence there is need to include the intercept when checking for unit root and running the correlogram. The graph also contains a trend thus when running the variable a trend must be included as well. The variable is not stationary because it does not have a mean of zero and its variance is not constant hence it has to be differenced to make it stationary since it has a stochastic trend. In addition, we observe that the last part of the graph has an upward sloping trend meaning that from around middle of 2017 till August 2018 the inflation of Turkey started to increase. Therefore we have lag CPI in order to make it stationary. 


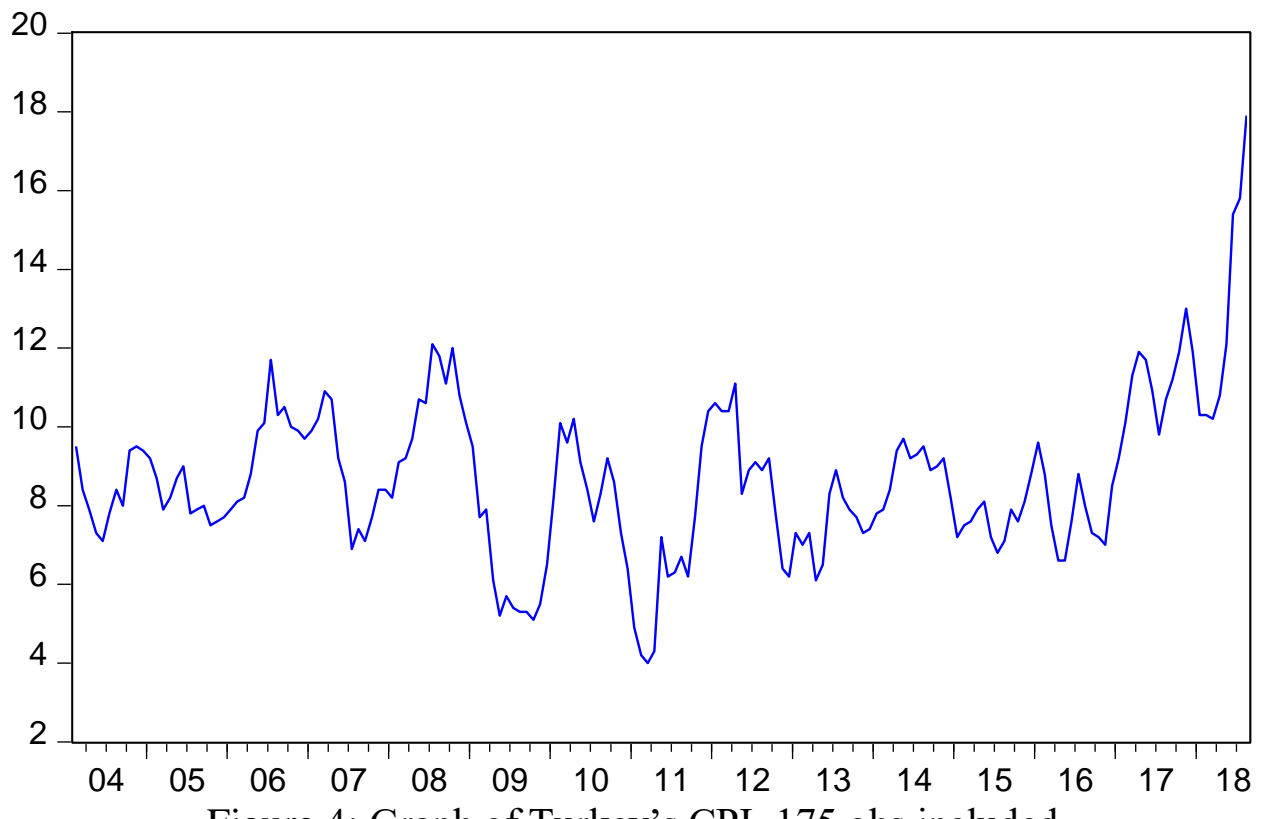

Figure 4: Graph of Turkey's CPI, 175 obs included

Source: Author's own illustration LAG15CPI

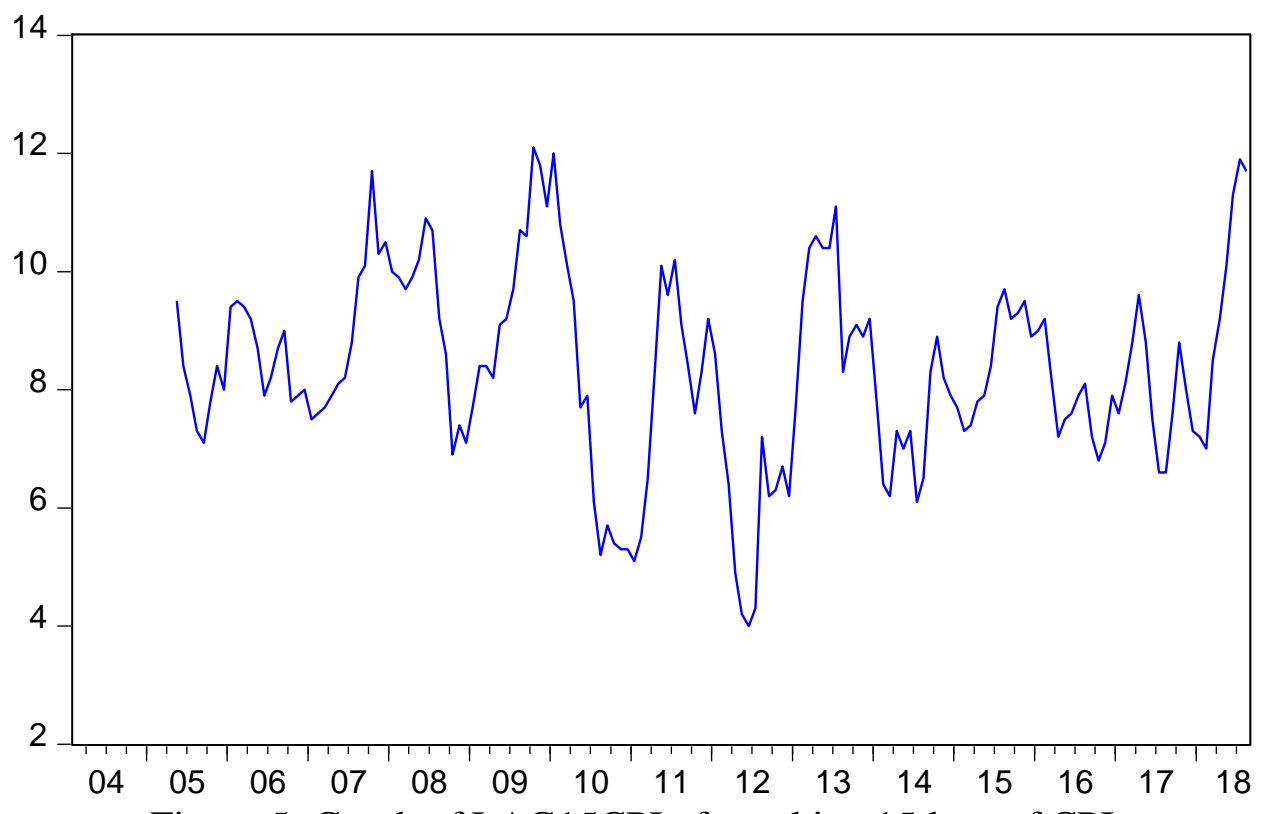

Figure 5: Graph of LAG15CPI after taking 15 lags of CPI

Source: Author's own illustration

In this paper Fig 5 above shows the graph of CPI after taking 15 lags to make it stationary. LAG15CPI has a stochastic trend hence will be differenced to make it stationary.

4.2 ADF unit root test

Table 2: Results of the ADF unit root test from Eviews

\begin{tabular}{|l|l|l|}
\hline VARIABLES & TRY/USD & LAG15CPI \\
\hline
\end{tabular}




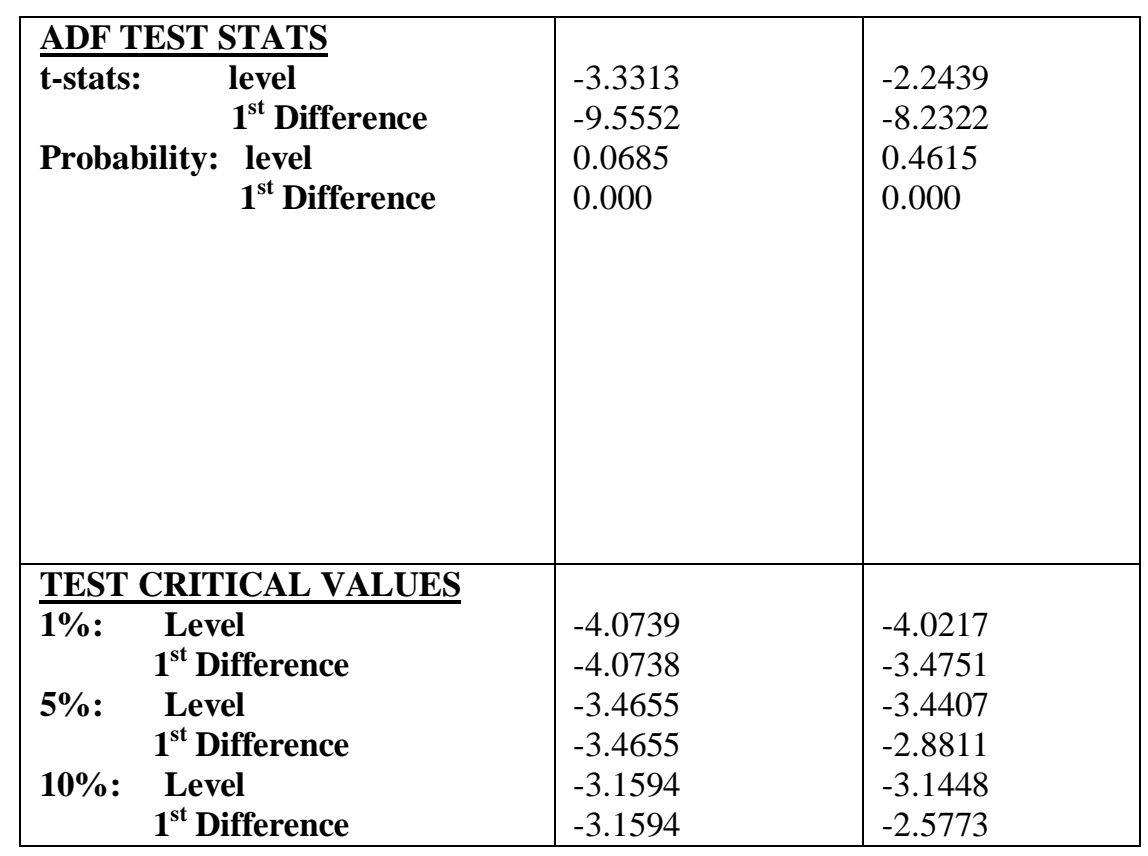

This paper starts by running variables using Augmented Dickey-Fuller test to test for unit root. It must be noted that the Null hypothesis (H0) states that: The variable has a unit root and the Alternative hypothesis (H1) states that: The variable has no unit root. This paper in Table 2 above shows the results of Turkey's exchange rate and CPI after run on Eviews at level and first difference. At level all the variables shows that they have unit root because their probability values are above $1 \%$, and $5 \%$ level of significant. At first difference the variables has no unit root because their p-values are significant at $1 \%$, and $5 \%$ level of significant and this is in line with the Difference Stationary-Process which states that if a variable has unit root it is stationary at first difference.

Table 3: Results of the Philips - Perron unit root test from Eviews

\begin{tabular}{|c|c|c|}
\hline VARIABLES & TRY/USD & LAG15CPI \\
\hline $\begin{array}{ll}\text { PP TEST STATS } \\
\text { t-stats: } & \begin{array}{l}\text { level } \\
\\
\text { Probability: }\end{array} \\
& \begin{array}{l}1^{\text {st }} \text { Difference } \\
\text { level } \\
1^{\text {st }} \text { Difference }\end{array} \\
\end{array}$ & $\begin{array}{l}-3.1431 \\
-9.4294 \\
0.1034 \\
0.0000\end{array}$ & $\begin{array}{l}-3.5088 \\
-10.5469 \\
0.0418 \\
0.0000\end{array}$ \\
\hline $\begin{array}{ll}\text { TEST } & \text { CRITICAL VALUES } \\
1 \%: & \text { Level } \\
& 1^{\text {st }} \text { Difference } \\
5 \%: & \text { Level } \\
& 1^{\text {st }} \text { Difference } \\
10 \%: & \text { Level } \\
& 1^{\text {st }} \text { Difference }\end{array}$ & $\begin{array}{l}-4.0724 \\
-4.0739 \\
-3.4649 \\
-3.4655 \\
-3.1590 \\
-3.1594\end{array}$ & $\begin{array}{l}-4.0168 \\
-4.0172 \\
-3.4383 \\
-3.4385 \\
-3.1435 \\
-3.1436\end{array}$ \\
\hline
\end{tabular}

In order to verify the unit root results produced by ADF this paper also make use of the Phillips-Perron unit root test. H0 states that the variable has a unit root whereas $\mathrm{H} 1$ states that the variable has no unit root. At $1 \%$ level of significant both variables are insignificant, they have a unit root. At $5 \%$ level of significant TRY/USD is insignificant and contains a unit root whereas LAG15CPI is significant because its p-value is less that 5\%. At first difference however all the variables are significant at $1 \%$ and $5 \%$ level of significant.

\subsection{ACF, PACF and Sample Correlogram}

Under the ACF, PACF function and the Sample correlogram, it is of paramount importance to know that H0 states that the variable is stationary and $\mathrm{H} 1$ states that the variable is non-stationary. The sample correlogram 
and the ACF and PACF function is the most important part in this analysis because it helps identify the proper ARIMA model to use for forecasting. Identification is the first stage of the Box and Jenkins methodology according to Adhikari and Agrawal (2009). It is the ACF and PACF model that helps find the tentative models that can be used in the second stage of estimation. Here the number of parameters to include as well as the model orders is obtained.

Table 4 below shows all the results of the ACF, PACF and the probability obtained from the sample correlogram of all variables at level and at first difference. At level the probability values of variables is zero hence reject the null hypothesis and accept alternative hypothesis which says that the variable is nonstationary. Secondly the values of ACF and PACF are too large, the spikes of the ACF and the PACF are large overlapping the $95 \%$ confidence interval dotted lines indicating that the variable is non-stationary otherwise the spikes should be confined within the $95 \%$ confidence dotted lines for the variable to be stationary.

This paper provides that at first difference all variables have become stationary. The probability values are now greater than $5 \%$ hence accept $\mathrm{H} 0$ which states that, the variable is stationary. The values of the ACF and PACF are now relatively smaller and the spikes of the correlogram are confined within the $95 \%$ confidence interval dotted lines hovering around zero.

Table 4: Sample correlogram results from Eviews

\begin{tabular}{|c|c|c|c|c|c|c|c|c|c|c|}
\hline LAGS & 1 & 2 & 3 & 4 & 5 & 6 & 7 & 8 & 9 & 10 \\
\hline $\begin{array}{l}\text { TRY/USD } \\
\text { ACF: Level } \\
1^{\text {st }} \text { Difference } \\
\text { PACF: Level } \\
1^{\text {st }} \text { Difference } \\
\text { Prob: Level } \\
1^{\text {st }} \text { Difference }\end{array}$ & $\begin{array}{l}0.943 \\
0.056 \\
0.943 \\
0.056 \\
0.000 \\
0.605\end{array}$ & $\begin{array}{l}0.864 \\
-0.22 \\
-0.23 \\
-0.23 \\
0.000 \\
0.090\end{array}$ & $\begin{array}{l}0.817 \\
-0.19 \\
0.304 \\
-0.17 \\
0.000 \\
0.043\end{array}$ & $\begin{array}{l}0.796 \\
0.135 \\
0.079 \\
0.109 \\
0.000 \\
0.044\end{array}$ & $\begin{array}{l}0.769 \\
0.043 \\
-0.05 \\
-0.05 \\
0.000 \\
0.076\end{array}$ & $\begin{array}{l}0.726 \\
-0.07 \\
-0.05 \\
-0.06 \\
0.000 \\
0.106\end{array}$ & $\begin{array}{l}0.690 \\
-0.04 \\
0.097 \\
0.009 \\
0.000 \\
0.155\end{array}$ & $\begin{array}{l}0.660 \\
-0.04 \\
-0.07 \\
-0.10 \\
0.000 \\
0.209 \\
\end{array}$ & $\begin{array}{l}0.632 \\
-0.20 \\
0.035 \\
-0.25 \\
0.000 \\
0.097\end{array}$ & $\begin{array}{l}0.621 \\
-0.05 \\
0.178 \\
-0.06 \\
0.000 \\
0.131\end{array}$ \\
\hline $\begin{array}{l}\text { LAG15CPI } \\
\text { ACF: Level } \\
1^{\text {st }} \text { Difference } \\
\text { PACF: Level } \\
1^{\text {st }} \text { Difference } \\
\text { Prob: Level } \\
1^{\text {st }} \text { Difference }\end{array}$ & $\begin{array}{l}0.855 \\
0.160 \\
0.855 \\
0.160 \\
0.000 \\
0.042\end{array}$ & $\begin{array}{l}0.670 \\
0.065 \\
-0.22 \\
0.041 \\
0.000 \\
0.089\end{array}$ & $\begin{array}{l}0.474 \\
-0.01 \\
-0.13 \\
-0.03 \\
0.000 \\
0.180\end{array}$ & $\begin{array}{l}0.293 \\
-0.19 \\
-0.06 \\
-0.19 \\
0.000 \\
0.023\end{array}$ & $\begin{array}{l}0.171 \\
0.024 \\
0.084 \\
0.093 \\
0.000 \\
0.043\end{array}$ & $\begin{array}{l}0.046 \\
0.040 \\
-0.17 \\
0.049 \\
0.000 \\
0.068\end{array}$ & $\begin{array}{l}-0.07 \\
-0.06 \\
-0.13 \\
-0.10 \\
0.000 \\
0.086\end{array}$ & $\begin{array}{l}-0.18 \\
0.045 \\
-0.05 \\
0.026 \\
0.000 \\
0.118\end{array}$ & $\begin{array}{l}-0.31 \\
-0.13 \\
-0.19 \\
-0.12 \\
0.000 \\
0.068\end{array}$ & $\begin{array}{l}-0.41 \\
-0.19 \\
-0.07 \\
-0.16 \\
0.000 \\
0.012\end{array}$ \\
\hline
\end{tabular}

In short this paper tend to concur on what is postulated in Gujarati (2004), that if a time series variable contains a unit root, it can only be made stationary by differencing following the Difference-Stationary Process.

\subsection{Nature of the variables after first difference (Stationary)}

After following the difference stationary process by differencing TRY/USD exchange rate once, to make it stationary as postulated in Gujarati (2004) Fig 6 shows that the exchange rate becomes stationary. $\mathrm{D}$ (TRY/USD) which is the first difference of the exchange rate of TRY and USD is now stationary having a mean of zero, an equal variance and covariance. Therefore, this paper provides that ARIMA(p,d,q) is the appropriate model to forecast this variable since it caters for the integrated process of making a variable stationary, Adhikari and Agrawal (2009). 


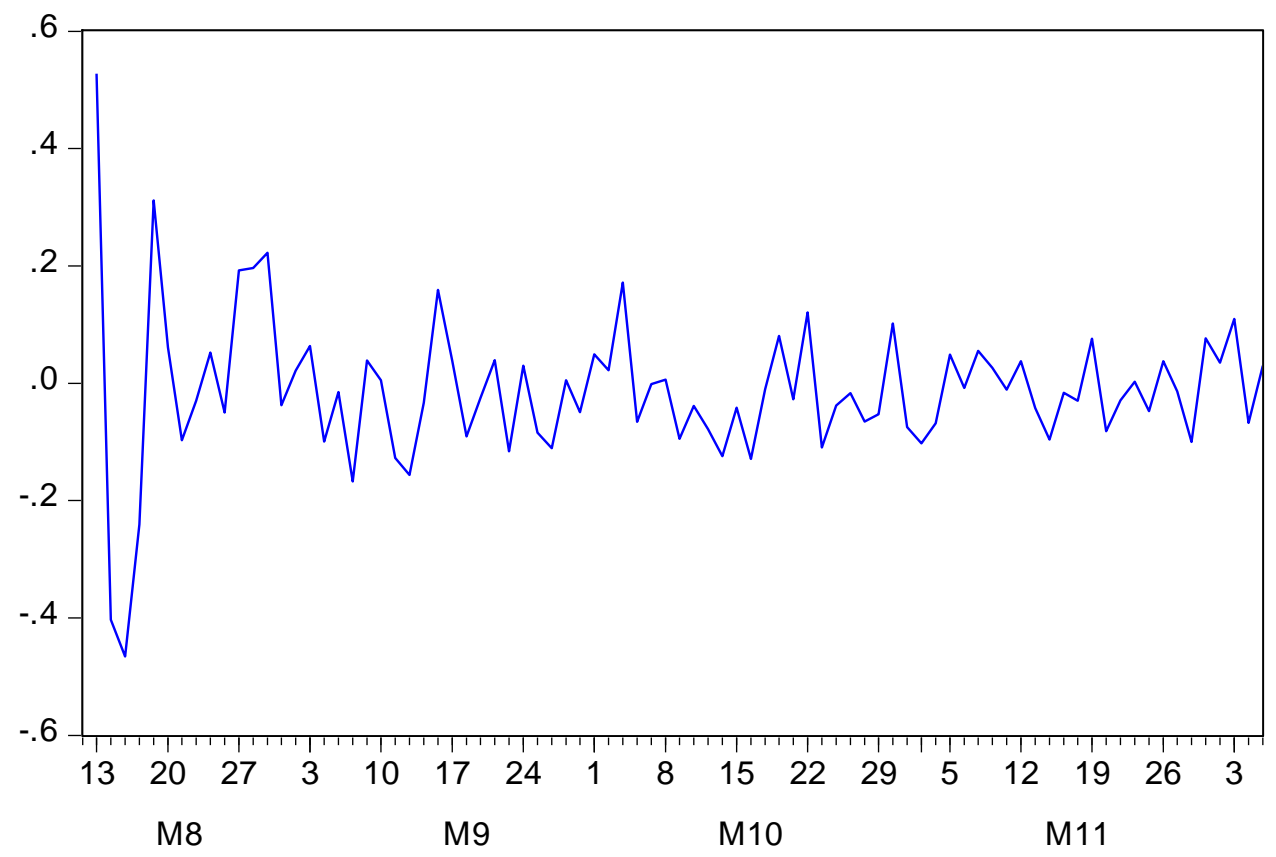

Figure 6: Graph showing the last group of TRY/USD at first difference

Source: Author's own graph

It is clear on the graph above that a horizontal line of best fit can be drawn from zero passing through the midst of all observations to the end. The graph shows that the variables now has an equal mean of zero because all the observations are now oscillating around zero and it shows that the variance of the variable is now the same.

\section{DLAG15CPI}

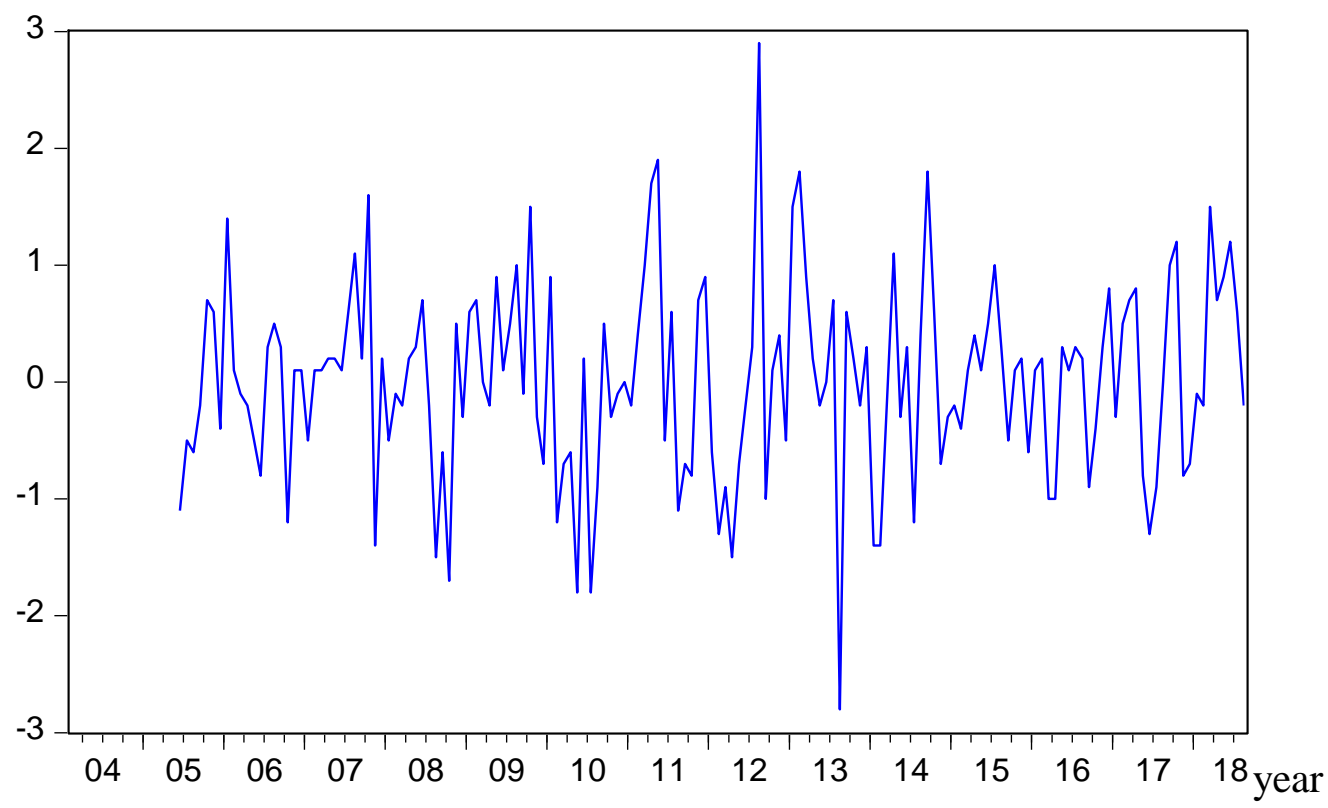

Figure 7: Graph of CPI at first difference

Source: Author's own graph

Fig 7 above shows the graph of the first difference of LAG15CPI which is now stationary after following the DSP. Therefore, it is D(LAG15CPI), first difference of lag15cpi, that is stationary and can be used to produce the model that can be used for forecasting purposes. Again since LAG15CPI has been differenced to make it stationary therefore, the best model to use is $\operatorname{ARIMA}(p, d, q)$ which caters for the process of differencing.

This paper in Fig 7 above just like Fig 6 shows that D(LAG15CPI) is now stationary because its mean is now equal to zero and it now have an equal variance. Fig 7 shows that a horizontal line of best fit can be 
drawn from 0 on the vertical axis showing that all variables has got an equal mean value of 0 and showing that the trend line is oscillating up and down in a uniform manner hence the variance is the same. Therefore, differencing of a variable makes it stationary.

\subsection{Selecting the best ARIMA model}

Adebayo, Sivasamy and Shangodoyin (2014) provides for the use of the Information Criterion such as AIC and SBIC to find the best ARIMA model to use in forecasting a financial time series data.

Identification is simply observing the behavior of the ACF, PACF and the sample correlogram to see which model to use. Sample correlograms of D(TRY/USD) and D(LAG15CPI) are used because it is the one that is stationary. Non-stationary variable cannot be used to find the ARIMA model because it has shocks and shocks never die, thus it's not fit for forecasting purposes. Table 4.5.1 below shows how the best ARIMA model from the sample correlogram.

Table 5: Identification of the best ARIMA to use Souce: Adebayo, Sivasamy and Shangodoyin (2014)

\begin{tabular}{|l|l|l|}
\hline Model & ACF pattern & PACF pattern \\
\hline AR(p) & Geometric decay of lag p \\
\hline MA(q) & Significant spike of q lag & Significant spike oemetric decay \\
\hline ARMA(p,q) & $\begin{array}{l}\text { Geometric decay (same pattern } \\
\text { with PACF) }\end{array}$ & $\begin{array}{l}\text { Geometric decay (same pattern } \\
\text { with PACF) }\end{array}$ \\
\hline
\end{tabular}

This paper in Table 5 above illustrates that for one to choose an Autoregressive AR(P) model the ACF should show an exponential decay towards zero whilst the PACF will be having significant spike at lag p. For one to follow Moving Average MA(q) model opposite results to those of the ACF should be observed from the correlogram; the ACF should have a significant spike at lag q while the PACF will have geometric decay towards zero. Lastly, for an ARMA(p,q) model to be chosen both the ACF and the PACF should show the same results.

In this case all variables after being made stationary by differencing, show the same pattern, geometric decay, for both the ACF and the PACF indicating that ARMA(p,q) model is appropriate, Adebayo et al (2014). In this paper ARIMA(p,d,q) is used since the variables has been differenced to become stationary (Adhikari and Agrawal, 2009). Therefore, this paper continues and produces tentative models from which the best model will be obtained. They are called tentative models because most appropriate model is not known (Farooqi, 2014); it is only after diagnostic testing that the best model is obtained. In the case of the first difference of LAG15CPI eight tentative models are provided, see table 6 below, which are estimated and the following results are obtained.

Table 6: CPI tentative models estimation results

\begin{tabular}{|l|l|l|l|l|l|}
\hline ARIMA & $\begin{array}{l}\text { Sig. } \\
\text { Coefficients }\end{array}$ & $\begin{array}{l}\text { Sigma } \\
\text { Square }\end{array}$ & Adj. R Square & AIC & BIC \\
\hline $\mathbf{1 , 1 , 1}$ & 0 & 0.6828 & 0.0080 & 2.505 & 2.583 \\
\hline $\mathbf{1 , 1 , 4}$ & 2 & 0.6458 & 0.0604 & 2.4535 & 2.5307 \\
\hline $\mathbf{1 , 1 , 5}$ & 1 & 0.6795 & 0.0115 & 2.5022 & 2.5794 \\
\hline $\mathbf{1 , 1 , 6}$ & 1 & 0.6213 & 0.0962 & 2.4442 & 2.5214 \\
\hline $\mathbf{4 , 1 , 1}$ & 2 & 0.6541 & 0.0484 & 2.4649 & 2.5421 \\
\hline $\mathbf{4 , 1 , 4}$ & 1 & 0.5278 & 0.2322 & 2.3157 & 2.3928 \\
\hline $\mathbf{4 , 1 , 5}$ & 1 & 0.6711 & 0.0238 & 2.4904 & 2.5676 \\
\hline $\mathbf{4 , 1 , 6}$ & 1 & 0.6305 & 0.0827 & 2.4582 & 2.5354 \\
\hline
\end{tabular}

According to Ariyo, Adewumi and Ayo (2014), the best model is obtained by checking the one with the most significant coefficients; highest adjusted R-square lowest sigma squared, which is the volatility and the lowest Akaike Information Criterion (AIC) and Bayesian Schwartz Information Criterion (BIC). This paper provides that $\operatorname{ARIMA}(1,1,4)$ and $\operatorname{ARIMA}(4,1,1)$ respectively are the best models to use for forecasting CPI because they have the most significant coefficients, high adjusted R-square, least volatility, lowest AIC and BIC value respectively as shown in the table above. It must be noted that ARIMA $(1,1,1)$ has got the highest adjusted R-square and the lowest volatility but, cannot pursue it since it does not have any significant coefficients and its AIC and BIC values are too high, therefore it's not the best model to use. ARIMA $(4,1,4)$ also has the lowest AIC and BIC values but its adjusted R-square is very small, it's volatility is also high 
compared to other models and it doesn't have the highest significant coefficients hence is not the best model. Therefore, it is $\operatorname{ARIMA}(1,1,4)$ and $\operatorname{ARIMA}(4,1,1)$ that provides the best fit to be used for forecasting.

Table 7: TRY/USD model estimation results

\begin{tabular}{|l|l|l|l|l|l|}
\hline ARIMA & Sig. Coeffients & $\begin{array}{l}\text { Sigma } \\
\text { Square }\end{array}$ & Adj. R Square & AIC & BIC \\
\hline $\mathbf{1 , 1 , 1}$ & 1 & 0.0145 & 0.0623 & -1.269 & -1.152 \\
\hline $\mathbf{1 , 1 , 2}$ & 1 & 0.0150 & 0.0302 & -1.261 & -1.144 \\
\hline $\mathbf{1 , 1 , 3}$ & 1 & 0.0141 & 0.0915 & -1.3178 & -1.201 \\
\hline $\mathbf{1 , 1 , 4}$ & 1 & 0.0152 & 0.0199 & -1.246 & -1.129 \\
\hline $\mathbf{2 , 1 , 1}$ & 1 & 0.0147 & 0.0501 & -1.280 & -1.164 \\
\hline $\mathbf{2 , 1 , 2}$ & 2 & 0.0143 & 0.0765 & -1.300 & -1.184 \\
\hline $\mathbf{2 , 1 , 3}$ & 2 & 0.0135 & 0.1283 & -1.359 & -1.243 \\
\hline $\mathbf{2 , 1 , 4}$ & 1 & 0.0145 & 0.0636 & -1.292 & -1.176 \\
\hline $\mathbf{3 , 1 , 1}$ & 2 & 0.0145 & 0.0632 & -1.291 & -1.174 \\
\hline $\mathbf{3 , 1 , 2}$ & 2 & 0.0143 & 0.0808 & -1.311 & -1.195 \\
\hline $\mathbf{3 , 1 , 3}$ & 2 & 0.0136 & 0.1242 & -1.343 & -1.227 \\
\hline $\mathbf{3 , 1 , 4}$ & 1 & 0.0143 & 0.0814 & -1.308 & -1.191 \\
\hline $\mathbf{4 , 1 , 1}$ & 2 & 0.0153 & 0.0165 & -1.244 & -1.128 \\
\hline $\mathbf{4 , 1 , 2}$ & 1 & 0.0147 & 0.0536 & -1.283 & -1.167 \\
\hline $\mathbf{4 , 1 , 3}$ & 1 & 0.0139 & 0.1069 & -1.334 & -1.217 \\
\hline $\mathbf{4 , 1 , 4}$ & 1 & 0.0131 & 0.1587 & -1.3131 & -1.1965 \\
\hline
\end{tabular}

Table 7 above shows the results of the tentative models of the first difference of TRY/USD. From the table below $\operatorname{ARIMA}(2,1,3)$ and $\operatorname{ARIMA}(3,1,3)$ are the most appropriate models since they have the most significant coefficients, highest R-square value and the least volatility, AIC and BIC values respectively.

The best model from the tentative models up to this point has been obtained. Thus the third stage of diagnostic testing is left to check if there is no other information that is left out. If the model is the best and if there is no other information that is left out the residual diagnostic correlogram should be flat, that is, it should be within the standard error bound indicated by the broken line on the correlogram, its ACF and PACF values should be stationary (Ariyo et al, 2014). If the residual diagnostic correlogram happens to have a significant spike then repeat again the three stages of model identification until the best model is obtained for forecasting Adhikari and Agrawal (2009). However, great care has to be taken to avoid over-fitting the model.

\subsection{Diagnostics tests of the selected ARIMA models}

This paper in the table below shows the ACF, PACF and p-value results obtained after running the residual diagnostic tests of $\operatorname{ARIMA}(2,1,3)$ model which has been selected in the section above for use in the forecasting of TRY/USD foreign exchange rate. Table 8 shows that the residual correlogram of is flat because its ACF and PACF values a relatively small less than 1 and its p-values are insignificant greater than $1 \%$ and $5 \%$ level of significant showing that $\operatorname{ARIMA}(2,1,3)$ is stationary.

Table 8: Residual diagnostic test for $\operatorname{ARIMA}(2,1,3)$

\begin{tabular}{|l|l|l|l|}
\hline LAGS & ACF & PACF & Prob. \\
\hline $\mathbf{1}$ & 0.063 & 0.063 & \\
\hline $\mathbf{2}$ & 0.093 & 0.089 & \\
\hline $\mathbf{3}$ & 0.166 & 0.157 & 0.060 \\
\hline $\mathbf{4}$ & 0.061 & 0.037 & 0.145 \\
\hline $\mathbf{5}$ & -0.022 & -0.057 & 0.271 \\
\hline $\mathbf{6}$ & -0.073 & -0.109 & 0.354 \\
\hline $\mathbf{7}$ & -0.074 & -0.081 & 0.426 \\
\hline $\mathbf{8}$ & -0.110 & -0.084 & 0.417 \\
\hline $\mathbf{9}$ & -0.233 & -0.193 & 0.128 \\
\hline $\mathbf{1 0}$ & -0.040 & 0.020 & 0.180 \\
\hline $\mathbf{1 1}$ & -0.088 & -0.021 & 0.204 \\
\hline $\mathbf{1 2}$ & 0.018 & 0.103 & 0.272 \\
\hline $\mathbf{1 3}$ & 0.062 & 0.095 & 0.322 \\
\hline $\mathbf{1 4}$ & 0.004 & -0.011 & 0.400 \\
\hline $\mathbf{1 5}$ & 0.070 & 0.006 & 0.441 \\
\hline $\mathbf{1 6}$ & -0.031 & -0.122 & 0.512 \\
\hline $\mathbf{1 7}$ & -0.049 & -0.018 & 0.568 \\
\hline
\end{tabular}




\begin{tabular}{|l|l|l|l|}
\hline $\mathbf{1 8}$ & -0.129 & -0.211 & 0.507 \\
\hline $\mathbf{1 9}$ & -0.058 & -0.052 & 0.551 \\
\hline $\mathbf{2 0}$ & 0.151 & 0.207 & 0.444 \\
\hline
\end{tabular}

In the Table 9 below the ACF, PACF and p-value results of the residual diagnostic tests of $\operatorname{ARIMA}(3,1,3)$ model of forecasting TRY/USD foreign exchange rate are shown. Table 9 shows that the residual correlogram of is flat because its ACF and PACF values a relatively small less than 1 and its p-values are insignificant greater than $1 \%$, and $5 \%$ level of significant showing that $\operatorname{ARIMA}(3,1,3)$ is stationary.

Table 9: Residual diagnostic test for $\operatorname{ARIMA}(3,1,3)$

\begin{tabular}{|l|l|l|l|}
\hline LAGS & ACF & PACF & Prob. \\
\hline $\mathbf{1}$ & 0.016 & 0.016 & \\
\hline $\mathbf{2}$ & -0.210 & -0.210 & \\
\hline $\mathbf{3}$ & 0.081 & 0.093 & 0.035 \\
\hline $\mathbf{4}$ & 0.093 & 0.046 & 0.074 \\
\hline $\mathbf{5}$ & -0.021 & 0.011 & 0.154 \\
\hline $\mathbf{6}$ & 0.058 & 0.084 & 0.235 \\
\hline $\mathbf{7}$ & -0.033 & -0.056 & 0.341 \\
\hline $\mathbf{8}$ & -0.074 & -0.049 & 0.405 \\
\hline $\mathbf{9}$ & -0.093 & -0.126 & 0.430 \\
\hline $\mathbf{1 0}$ & -0.044 & -0.072 & 0.518 \\
\hline $\mathbf{1 1}$ & -0.030 & -0.056 & 0.610 \\
\hline $\mathbf{1 2}$ & 0.101 & 0.111 & 0.603 \\
\hline $\mathbf{1 3}$ & 0.036 & 0.055 & 0.677 \\
\hline $\mathbf{1 4}$ & 0.003 & 0.076 & 0.753 \\
\hline $\mathbf{1 5}$ & 0.091 & 0.119 & 0.753 \\
\hline $\mathbf{1 6}$ & -0.013 & -0.042 & 0.812 \\
\hline $\mathbf{1 7}$ & 0.005 & 0.018 & 0.862 \\
\hline $\mathbf{1 8}$ & -0.114 & -0.222 & 0.827 \\
\hline $\mathbf{1 9}$ & -0.016 & -0.047 & 0.870 \\
\hline $\mathbf{2 0}$ & 0.175 & 0.132 & 0.718 \\
\hline
\end{tabular}

The table below shows the ACF, PACF and p-value results of the residual diagnostic tests of ARIMA $(1,1,4)$ model which has been selected in the section above for use in the forecasting of Turkey's CPI a major factor that determines foreign exchange rate in the FEM. Table 10 shows that the residual diagnostic correlogram of ARIMA $(1,1,4)$ is flat because its ACF and PACF values are relatively small within the range -1 to 1 and its p-values are insignificant greater than $1 \%$, and $5 \%$ level of significant showing that $\operatorname{ARIMA}(1,1,4)$ is stationary.

Table 10: Residuals diagnostics tests of $\operatorname{ARIMA}(1,1,4)$ for LAG15CPI

\begin{tabular}{|l|l|l|l|}
\hline LAGS & ACF & PACF & Prob. \\
\hline $\mathbf{1}$ & -0.010 & -0.010 & \\
\hline $\mathbf{2}$ & 0.063 & 0.063 & \\
\hline $\mathbf{3}$ & -0.024 & -0.023 & 0.384 \\
\hline $\mathbf{5}$ & 0.050 & 0.046 & 0.556 \\
\hline $\mathbf{6}$ & 0.012 & 0.016 & 0.754 \\
\hline $\mathbf{7}$ & 0.009 & 0.003 & 0.876 \\
\hline $\mathbf{8}$ & -0.089 & -0.089 & 0.771 \\
\hline $\mathbf{9}$ & -0.041 & -0.046 & 0.830 \\
\hline $\mathbf{1 0}$ & -0.113 & -0.106 & 0.658 \\
\hline $\mathbf{1 1}$ & -0.180 & -0.188 & 0.227 \\
\hline
\end{tabular}

The Table 11 below shows the ACF, PACF and p-value results of the residual diagnostic tests of ARIMA(4,1,1) model which has been selected in the section above for use in forecasting of CPI of Turkey which is a factor that determines foreign exchange rate in the Foreign Exchange Market. Table 11 shows that the residual correlogram of ARIMA $(4,1,1)$ is flat because its ACF and PACF values are relatively small within the range of -1 to 1 and its p-values are insignificant greater than $1 \%$, and $5 \%$ level of significant showing that $\operatorname{ARIMA}(4,1,1)$ is stationary. 
Table 11: Residuals diagnostics test of ARIMA(4,1,1) for LAG15CPI

\begin{tabular}{|l|l|l|l|}
\hline LAGS & ACF & PACF & Prob. \\
\hline $\mathbf{1}$ & 0.014 & 0.014 & \\
\hline $\mathbf{2}$ & 9.092 & 0.092 & \\
\hline $\mathbf{3}$ & -0.015 & -0.018 & 0.227 \\
\hline $\mathbf{4}$ & 0.004 & -0.004 & 0.482 \\
\hline $\mathbf{5}$ & 0.024 & 0.028 & 0.669 \\
\hline $\mathbf{6}$ & 0.020 & 0.019 & 0.804 \\
\hline $\mathbf{7}$ & -0.096 & -0.102 & 0.674 \\
\hline $\mathbf{8}$ & -0.070 & -0.072 & 0.676 \\
\hline $\mathbf{9}$ & -0.114 & -0.095 & 0.513 \\
\hline $\mathbf{1 0}$ & -0.192 & -0.188 & 0.127 \\
\hline $\mathbf{1 1}$ & -0.016 & -0.003 & 0.181 \\
\hline
\end{tabular}

At this juncture we the diagnostic tests of the squared residual correlogram of ARIMA $(1,1,4)$ and $\operatorname{ARIMA}(4,1,1)$ to make sure if really these models are appropriate as has been suggested by the residual correlogram tests results above is run. Table 12 and table 13 below shows the results of ARIMA $(1,1,4)$ and ARIMA(4.1.1) respectively indicating that the squared residual correlogram of ARIMA $(1,1,4)$ and ARIMA(4,1,1) are flat and Table 12 and Table 13 below indicates that the ACF and PACF values of the squared residual of $\operatorname{ARIMA}(1,14)$ and $\operatorname{ARIMA}(4,1,1)$ are within the required bound -1 to 1 . The p-values as well are insignificant showing that the squared residuals are stationary.

Table 12: Residuals Squared diagnostics test of ARIMA $(1,1,4)$ for LAG15CPI

\begin{tabular}{|l|l|l|l|}
\hline & ACF & PACF & Prob. \\
\hline $\mathbf{1}$ & 0.097 & 0.097 & 0.217 \\
\hline $\mathbf{2}$ & -0.050 & -0.060 & 0.379 \\
\hline $\mathbf{3}$ & -0.112 & -0.102 & 0.263 \\
\hline $\mathbf{4}$ & -0.060 & -0.043 & 0.333 \\
\hline $\mathbf{5}$ & 0.039 & 0.039 & 0.435 \\
\hline $\mathbf{6}$ & 0.201 & 0.183 & 0.071 \\
\hline $\mathbf{7}$ & -0.001 & -0.045 & 0.113 \\
\hline $\mathbf{8}$ & -0.119 & -0.100 & 0.081 \\
\hline $\mathbf{9}$ & 0.075 & 0.143 & 0.091 \\
\hline $\mathbf{1 0}$ & 0.010 & -0.003 & 0.132 \\
\hline $\mathbf{1 1}$ & 0.123 & 0.101 & 0.090 \\
\hline
\end{tabular}

Table 13: Residuals Squared diagnostics test of ARIMA $(4,1,1)$ for LAG15CPI

\begin{tabular}{|l|l|l|l|}
\hline & ACF & PACF & Prob. \\
\hline $\mathbf{1}$ & 0.077 & 0.077 & 0.328 \\
\hline $\mathbf{2}$ & -0.046 & -0.052 & 0.521 \\
\hline $\mathbf{3}$ & -0.110 & -0.103 & 0.350 \\
\hline $\mathbf{4}$ & -0.080 & -0.068 & 0.361 \\
\hline $\mathbf{5}$ & 0.065 & 0.168 & 0.409 \\
\hline $\mathbf{6}$ & 0.283 & 0.160 & 0.100 \\
\hline $\mathbf{7}$ & 0.008 & -0.026 & 0.155 \\
\hline $\mathbf{8}$ & -0.100 & -0.084 & 0.137 \\
\hline $\mathbf{9}$ & 0.059 & 0.118 & 0.166 \\
\hline $\mathbf{1 0}$ & -0.004 & 0.000 & 0.228 \\
\hline $\mathbf{1 1}$ & 0.109 & 0.080 & 0.183 \\
\hline
\end{tabular}

\subsection{Forecasting and forecast performance measures}

The essence of using ARIMA model is basically to forecast future values of the time series variable such as exchange rate and CPI in this case. The idea behind the model is to make use of past values to predict the future and by so doing the series speak for itself. This is the best method of forecasting time series variable. Diagnostic tests have also been applied after selecting the best ARIMA to make sure that there is no other information that has been left out. 


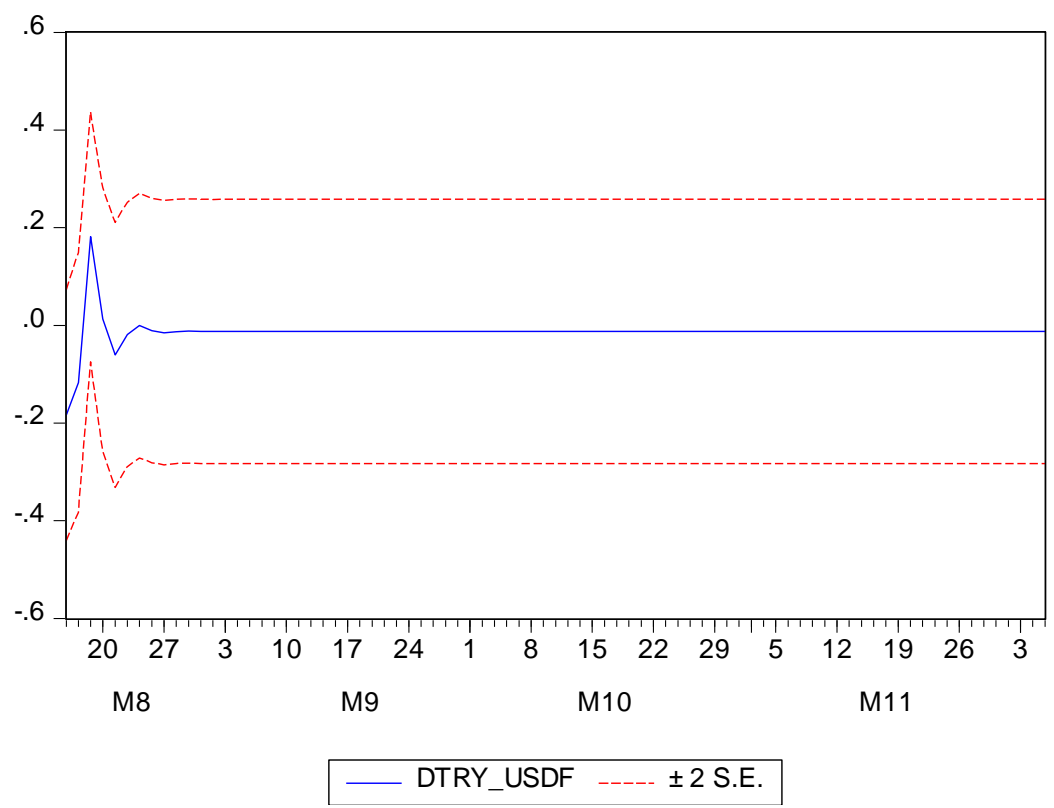

Forecast: DTRY_USDF

Actual: DTRY_USD

Forecast sample: 8/10/2018 12/05/2018

Adjusted sample: 8/15/2018 12/05/2018

Included observations: 81

Root Mean Squared Error 0.088391

Mean Absolute Error

0.067854

Mean Abs. Percent Error 112.8364

Theil Inequality Coefficient 0.629896

Bias Proportion

0.000050

Variance Proportion

0.689447

Covariance Proportion

0.310503

Theil U2 Coefficient

0.915847

Symmetric MAPE

145.0016

Figure 8: Forecasting exchange rate with $\operatorname{ARIMA}(2,1,3)$

In this paper, Fig 8 above shows the forecasting results of $\operatorname{ARIMA}(2,1,3)$ obtained after running the model on Eviews 10. The figure above shows that the blue line is the forecasting results within the $+/-2 \%$ standard error bound as shown by the 2 red lines. If the actual results of the variable TRY/USD exchange rate fall within the 2 red lines of standard error we therefore conclude that the model is appropriate.

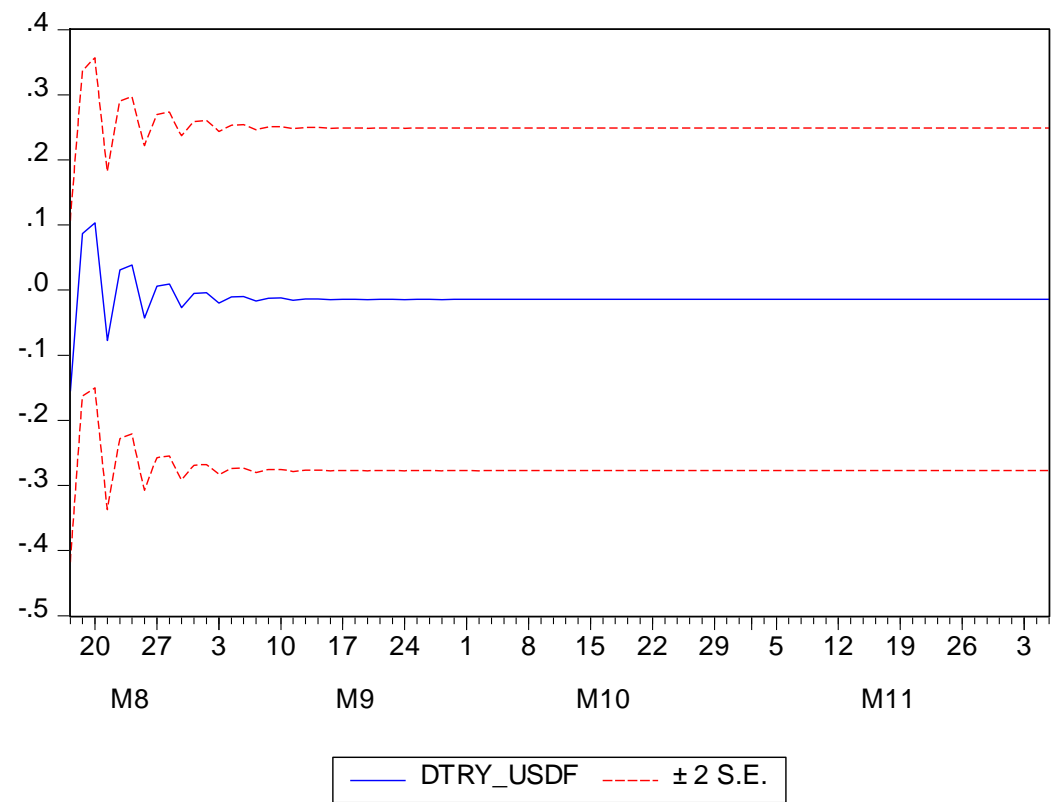

\begin{tabular}{|ll|}
\hline \multicolumn{2}{|l|}{ Forecast: DTRY_USDF } \\
Actual: DTRY_USD \\
Forecast sample: 8/10/2018 12/05/2018 \\
Adjusted sample: 8/16/2018 & $12 / 05 / 2018$ \\
Included observations: 80 & \\
Root Mean Squared Error & 0.084129 \\
Mean Absolute Error & 0.064890 \\
Mean Abs. Percent Error & 117.4575 \\
Theil Inequality Coefficient & 0.689181 \\
$\quad$ Bias Proportion & 0.002242 \\
Variance Proportion & 0.623458 \\
Covariance Proportion & 0.374300 \\
Theil U2 Coefficient & 0.914366 \\
Symmetric MAPE & 140.7503 \\
\hline
\end{tabular}

Figure 9: Forecasting exchange rate with $\operatorname{ARIMA}(3,1,3)$

The Fig 9 above shows the forecasting results of $\operatorname{ARIMA}(3,1,3)$ that was obtained after running the model on Eviews 10. The figure above shows the blue line which is the forecasting results within the $+/-2 \%$ standard error bound as shown by the 2 red lines. If the actual results of the variable TRY/USD exchange rate fall within the 2 red lines of standard error therefore, the model is appropriate. The table below shows the results of the forecasting performance measures of $\operatorname{ARIMA}(2,1,3)$ and $\operatorname{ARIMA}(3,1,3)$. This paper also made use of the five performance measures (RMSE, MAPE, MAE, Theil U statistics, and Bias proportion) as indicated in the table below.

Table 14 below shows that $\operatorname{ARIMA}(3,1,3)$ is the most appropriate model because it has the lowest values RMSE, MAE, and Theil U statistics having managed to score 3 out of the 5 performance measures. Still $\operatorname{ARIMA}(2,1,3)$ is not very bad its equally good because it has the least bias proportion indicating that it has got the least directional error, it also have the least MAPE result. $\operatorname{ARIMA}(3,1,3)$ has got the least size error values. Both models are a perfect fit since their Theil $U 2$ statistic is $0 \leq \mathrm{U} \leq 1$ (Adhikari \& Agrawal, 2009).

Table 14: Forecasting Performance Measures of $\operatorname{ARIMA}(2,1,3)$ and $\operatorname{ARIMA}(3,1,3)$ of Foreign Exchange Rate 


\begin{tabular}{|l|l|l|}
\hline & ARIMA(2,1,3) & ARIMA(3,1,3) \\
\hline Root Mean Squared Error & 0.0884 & 0.0841 \\
\hline Mean Absolute Error & 0.0679 & 0.0649 \\
\hline Mean Abs. Percent Error & 112.84 & 117.46 \\
\hline Theil U2 Coefficient & 0.9158 & 0.9144 \\
\hline Bias Proportion & 0.0001 & 0.0022 \\
\hline
\end{tabular}

Fig 10 and 11 below shows the forecasting results of $\operatorname{ARIMA}(2,1,3)$ and $\operatorname{ARIMA}(3,1,3)$ respectively plotted against the actual values of the TRY/USD foreign exchange rate. Both results in the two figures below show almost the same results. It can be observed from both graphs that from around 15 August till 25 August the models forecasted exactly the actual results and later shows a line of best fit on the actual results indicating that both models are the best in forecasting TRY/USD exchange rate.

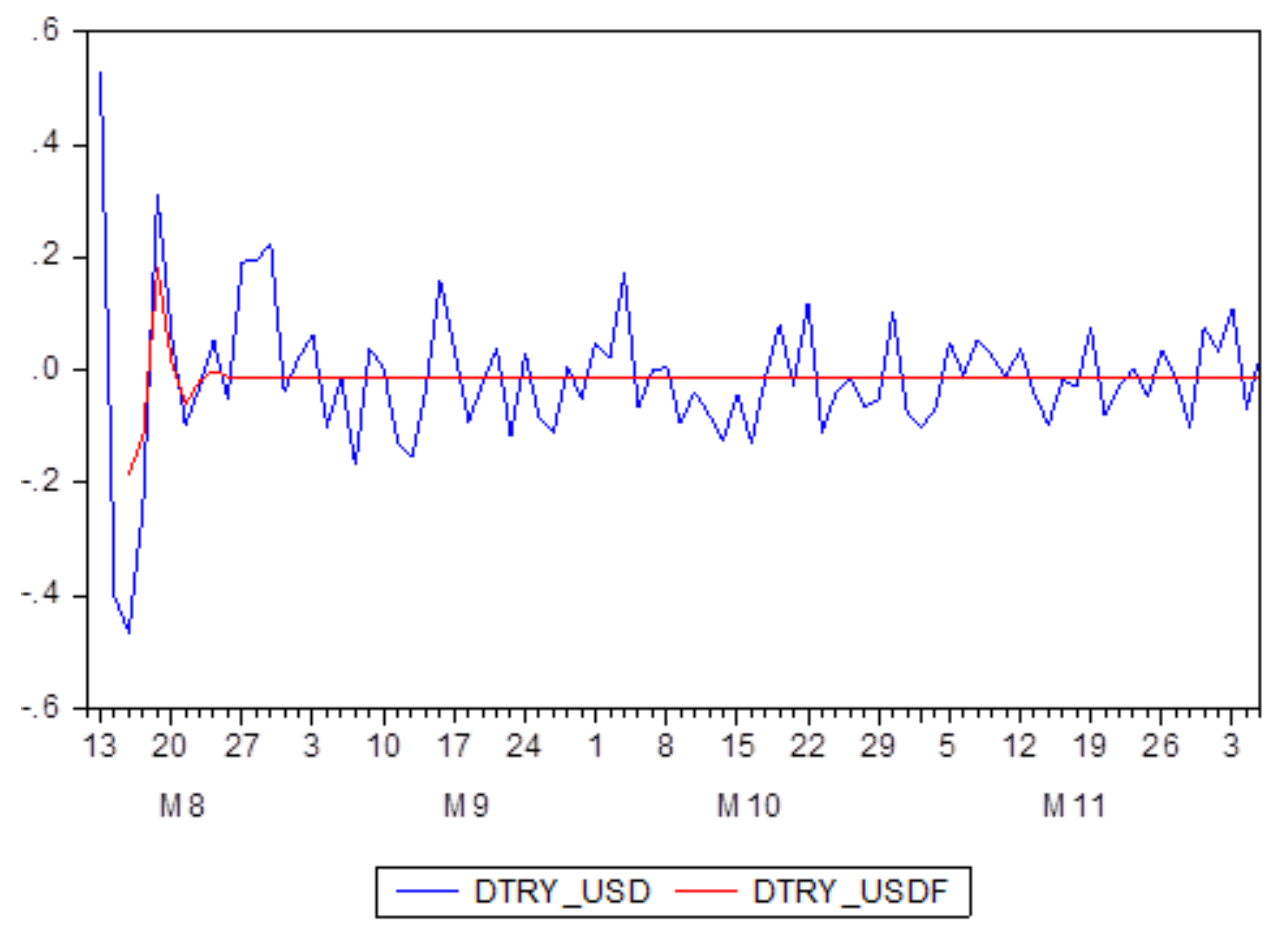

Figure 10: $\operatorname{ARIMA}(2,1,3)$ forecasting results plot with actual results 


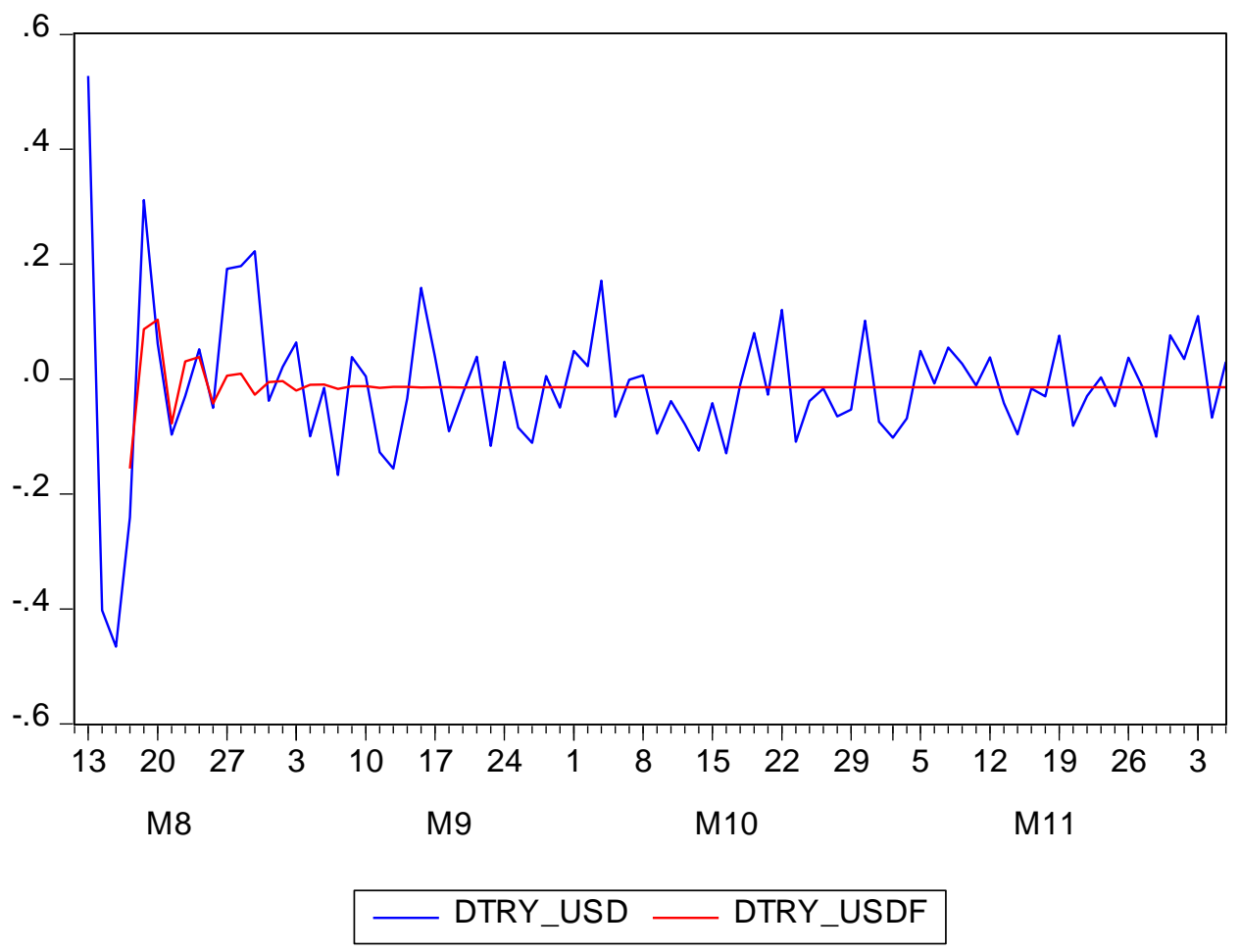

Figure 11: ARIMA(3,1,3) forecasting results plot with actual results

Fig 12 and Fig 13 below shows the forecasting results of $\operatorname{ARIMA}(1,1,4)$ and $\operatorname{ARIMA}(4,1,1)$ respectively that was obtained after running the models on Eviews 10. The figures show that the blue line is the forecasting results within the +/- $2 \%$ standard error bound as shown by the 2 red lines. If the actual results of the variable CPI, a major determinant of foreign exchange rate in the FEM, fall within the 2 red lines of standard error we therefore conclude that the model is appropriate. The models have also been subjected to the forecasting performance measures to see which model best predict the results of CPI.

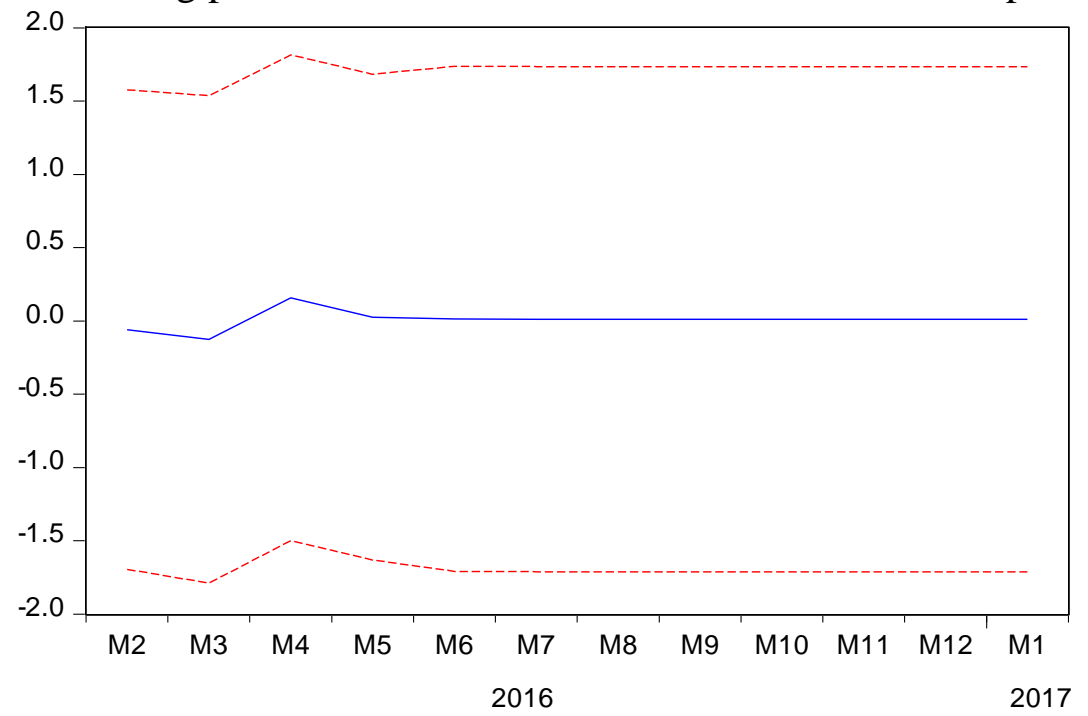

\begin{tabular}{|c|c|}
\hline \multicolumn{2}{|l|}{ Forecast: DLAG15CPIF } \\
\hline \multicolumn{2}{|l|}{ Actual: DLAG15CPI } \\
\hline \multicolumn{2}{|c|}{ Forecast sample: 2016M02 2017M01 } \\
\hline \multicolumn{2}{|l|}{ Included observations: 12} \\
\hline Root Mean Squared Error & 0.589622 \\
\hline Mean Absolute Error & 0.486700 \\
\hline Mean Abs. Percent Error & 100.4010 \\
\hline Theil Inequality Coefficient & 0.916291 \\
\hline Bias Proportion & 0.044022 \\
\hline Variance Proportion & 0.743538 \\
\hline Covariance Proportion & 0.212440 \\
\hline Theil U2 Coefficient & 0.847440 \\
\hline Symmetric MAPE & 185.3031 \\
\hline
\end{tabular}

— DLAG15CPIF ----- \pm 2 S.E.

Figure 12: ARIMA(1,1,4) forecasting results 


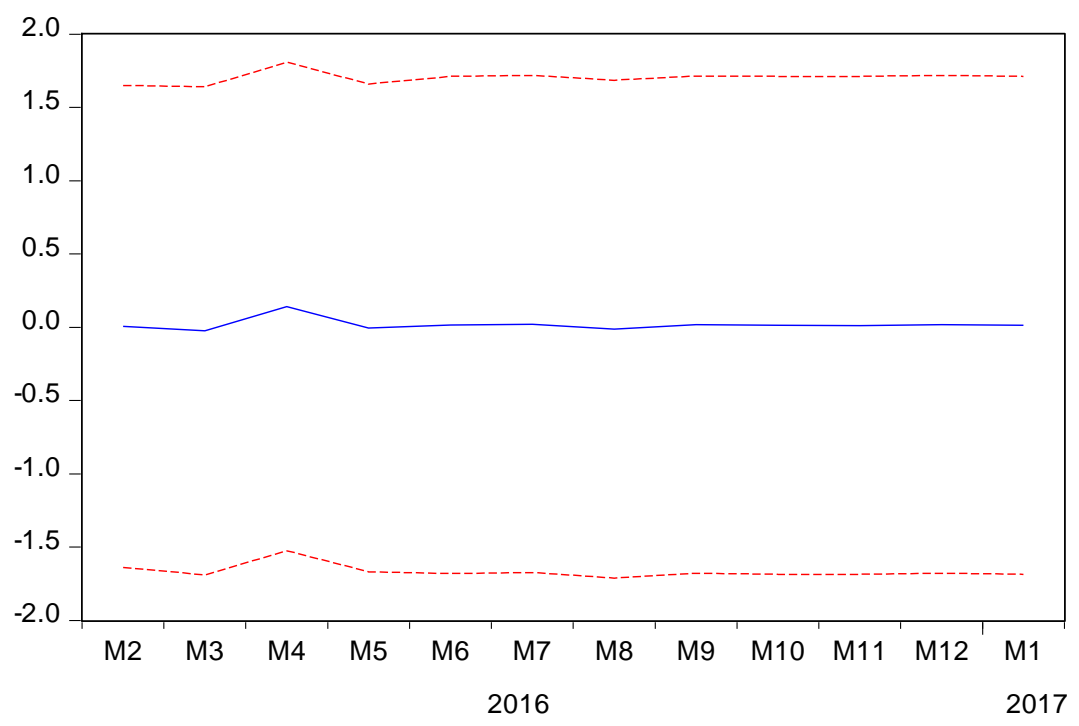

Forecast: DLAG15CPIF

Actual: DLAG15CPI

Forecast sample: 2016M02 2017M01 Included observations: 12

Root Mean Squared Error

0.599557

Mean Absolute Error

0.491996

Mean Abs. Percent Error 99.88707

Theil Inequality Coefficient 0.959473

Bias Proportion

0.049983

Variance Proportion

0.782240

Covariance Proportion

0.167777

Theil U2 Coefficient

0.878538

Symmetric MAPE

189.8635

\section{- DLAG15CPIF ----- \pm 2 S.E.}

Figure 13: ARIMA $(4,1,1)$ forecasting results

Table 15: Forecasting Performance Measures results of ARIMA(1,1,4) and ARIMA(4,1,1) of LAG15CPI

\begin{tabular}{|l|l|l|}
\hline & ARIMA(1,1,4) & ARIMA(4,1,1) \\
\hline Root Mean Squared Error & 0.5896 & 0.5996 \\
\hline Mean Absolute Error & 0.4867 & 0.4919 \\
\hline Mean Abs. Percent Error & 100.40 & 99.89 \\
\hline Theil U2 Coefficient & 0.8474 & 0.8785 \\
\hline Bias Proportion & 0.0440 & 0.0499 \\
\hline
\end{tabular}

In table 15 above ARIMA $(1,1,4)$ is the most appropriate one since it has the least RMSE, MAE, Theil U statistic and bias proportion. Arima $(1,1,4)$ has got the least values of both the forecasting error size and direction, therefore is the best model to use for forecasting inflation rate of Turkey. Fig 14 and Fig 15 below shows the results obtained by plotting the forecasting results of $\operatorname{ARIMA}(1,1,4)$ and $\operatorname{ARIMA}(4,1,1)$ respectively against the actual values of the first difference of LAG15CPI. Both models are a perfect fit because their Theil $\mathrm{U} 2$ statistic is within the range $0 \leq \mathrm{U} \leq 1$ according to Adhikari and Agrawal (2009).

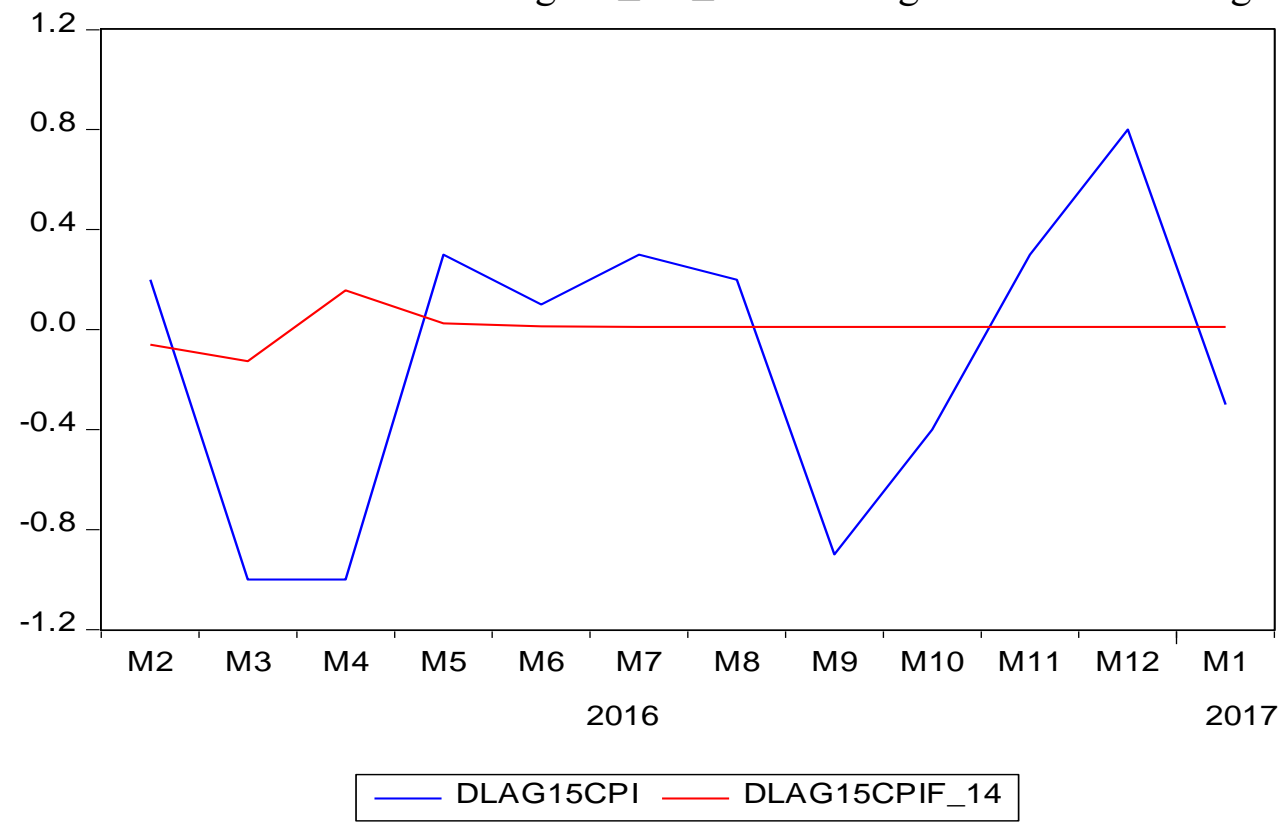

Figure 14: ARIMA(1,1,4) Forecasting results plotted against actual DLAG15CPI 


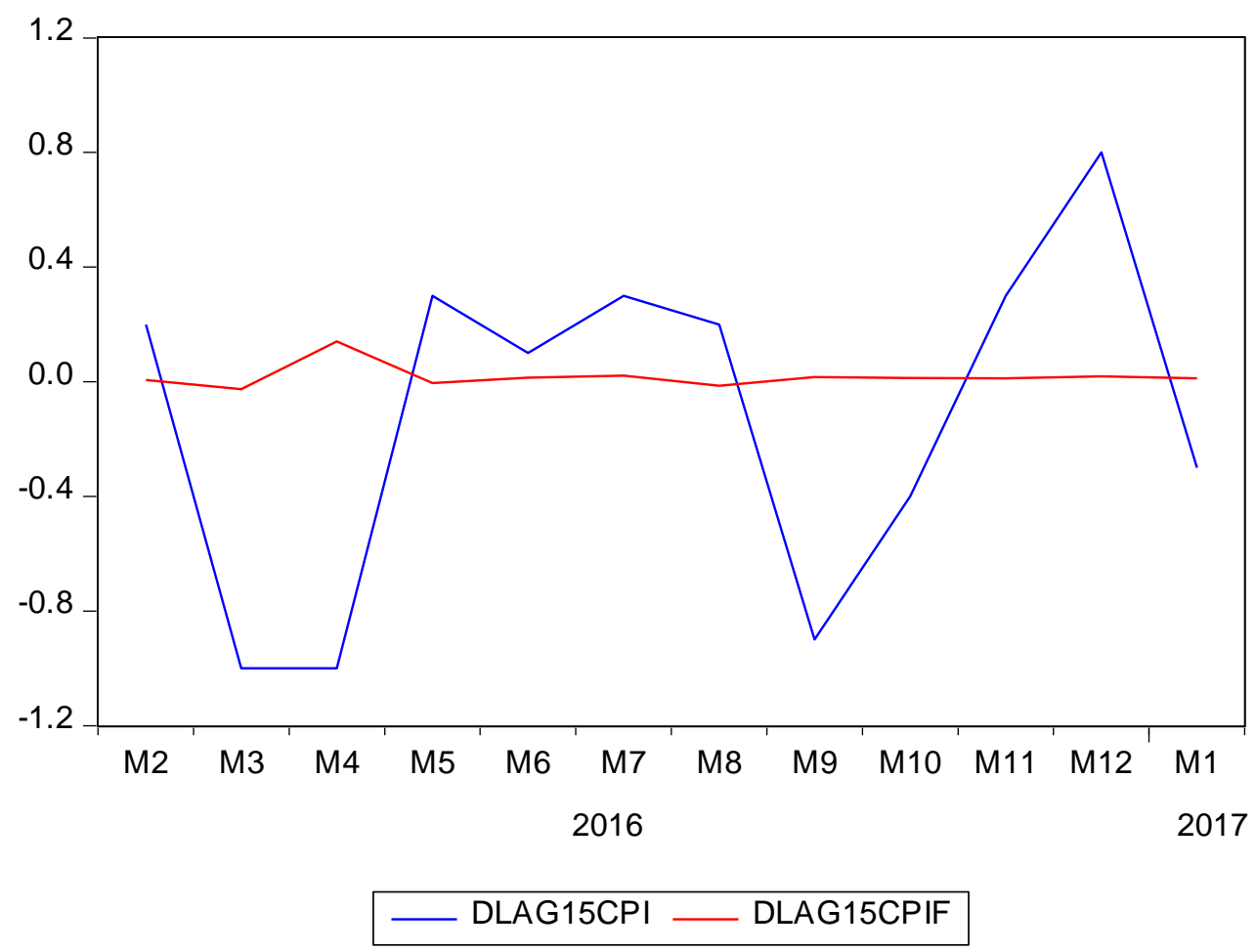

Figure 15: ARIMA(4,1,1) Forecasting results plotted against actual DLAG15CPI

In short, the B-J methodology is based on the fundamental of parsimony which tries to strike the balance between meagerness and stinginess and it states that parsimonious models basically give better results than that of an over-parameterized model. The idea behind is that including too many variables in a model tend to reduce the degrees of freedom hence a negative R-square may be obtained if care is not taken. There is no point in time when one can obtain a perfect ARIMA model because it is more of art than science, Gujarati (2004).

\section{Conclusion and Recommendations}

\subsection{Conclusion}

In conclusion, ARIMA model provides robust short term results that can be used to predict and forecast foreign exchange rate in the FEM of Turkey. By making use of $\operatorname{ARIMA}(p, d, q)$, socio-economic data that is normally non-stationary can now be forecasted after having been differenced. Thus in line with Adhikari and Agrawal (2009) and Waeto et al (2014), ARIMA model is used for variables that have been differenced to become stationary. This paper also provides that, ceteris Paribas, the foreign exchange rate of Turkey is going to have short run stability, that is, within the next 12 months.

This paper also postulates that the best ARIMA model for forecasting TRY/USD exchange rate is ARIMA $(3,1,3)$ because it has the least values of the three forecasting performance measures of RMSE, MAE and Theil U statistic indicating that it has the lowest forecasting error size, hence we pick the one with least error size than direction, Klimberg, et al (2015). ARIMA(2,1,3) has got the least MAPE and forecast bias indicating that it has got the least directional forecasting error. However, at the model estimation stage $\operatorname{ARIMA}(2,1,3)$ is the best model since it had the lowest AIC and BIC values as well as the least volatility. Therefore, these two models are equally correct and they can produce the same results because after plotting the forecasting results of both models against the actual results of TRY/USD exchange rate they gave the same results.

Furthermore, the best ARIMA model that can be used to forecast CPI of Turkey is ARIMA $(1,1,4)$. This model provides for the least forecasting performance measures result which is in line with the results found at the estimation stage by AIC, BIC, and Adjusted R-square. The results of the AIC and BIC are the same with those of the forecasting performance measures.

Moreover, the ARIMA model with the least forecasting performance results is the one that is the best model since it indicates that it has the minimum possible error in both size and direction and this is in line with Klimberg et al (2015) and Adhikari and Agrawal (2009). In line with Klimberg et al (2015) this paper 
provides if the bias proportion is closer to zero the model is the best and in this case all models have produced very small values of bias proportion. This paper concurs with Wallström (2009) that MAPE, since it includes a small denominate, tends to inflate the forecasting percentage errors thereby causing outliers as can be seen from the MAPE results in all models. Therefore, a very high value of MAPE does not actually mean that the model is bad. It is the sMAPE that is used to correct the errors found in the MAPE to give better results, Wallström (2009).

In addition to that, this paper concurs with Adhikari and Agrawal (2009) that ACF and PACF are the best functions that can be used for model identification which helps in coming up with tentative models that can be estimated to find the best model. ACF and PACF are also used at stage three of Box-Jenkins methodology of diagnostic testing. After running the residual diagnostic tests correlogram and the residual squared diagnostic test correlogram the ACF and PACF values are checked to see if they are flat and within the error bound. Therefore, this paper concludes that ACF and PACF plays a major role in coming up with the best ARIMA model otherwise a proper model cannot be obtained.

On top of that, this paper concurs with Farooqi (2014) who postulated that ARIMA model produces robust results for observations which are 50 and below. This so because in this study foreign exchange rate which has 84 observations was better forecasted than CPI which has 175 observations. The values of RMSE, MAE and Bias proportion of $\operatorname{ARIMA}(2,1,3)$ and $\operatorname{ARIMA}(3,1,3)$ models that has been selected to forecast exchange rate are smaller than the values of $\operatorname{ARIMA}(1,1,4)$ and $\operatorname{ARIMA}(4,1,1)$ models of forecasting CPI because CPI had many observations than exchange rate.

Finally, in line with Adhikari and Agrawal (2009) this paper concurs that AIC and BIC are very useful in the model selection process. The model with the least AIC and BIC value is the best model that can be used for forecasting purposes and the principle of parsimony is very crucial to avoid over-fitting the model, Farroqi (2014).

\subsection{Policy recommendations}

This paper recommend banks, investors, foreign exchange brokers and other participants in the Foreign Exchange Market of Turkey to make use of $\operatorname{ARIMA}(3,1,3)$ for forecasting exchange rate in their trading and investment decisions in order to be profitable. Government and policy makers of FEM should use $\operatorname{ARIMA}(3,1,3)$ in making FEM policies. ARIMA $(1,1,4)$ should be used for forecasting inflation rate $(\mathrm{CPI})$ of Turkey which is a major determinant of foreign exchange rate as this will help how the future inflation rate will affect the future foreign exchange rate. Lastly, with the passage of time we recommend for an update of these models with current data.

\subsection{Limitations of the study}

The limitation of this study is that it did not include other forecasting models, including several other hybrid models can help obtain robust forecasting results.

\subsection{Future recommendations}

For further studies on this topic we recommend the use of several other methods such as VAR and VECM of data analysis and other diagnostic tests to fully examine, evaluate and analyze the Turkey's Foreign Exchange Rate.

\section{References}

[1] Adebayo, F. A. Sivansamy, R. \& Shangdodoyn, K. (2014). "Forecasting Stock Market Series with ARIMA Model", Journal of Statistical and Econometric Methods, 3, 3, 65-77.

[2] Adhikari, R \& Agarwal, R. K. (2013). “An Introductory Study on Time Series Modeling and Forecasting”, arXiv preprint arXiv:1302.6613

[3] Akincilar, A., Temiz, I. \& Sahin, E. (2010). "The application of exchange rate forecasting in Turkey", Gazi University Journal of Science.

[4] Ariyo, A. A., Adewumi, A. O. \& Ayo, C. K. (2014). "Stock price prediction using the ARIMA model", 2014 UKSim-AMSS 16th International Conference on Computer Modelling and Simulation.

[5] Biswajit, M (2015). "Univariate forecasting of Indian exchange rates: a comparison", International Journal of Computational Economics and Econometrics, 5(3): 272 - 288. 
[6] Box, G.E.P. \& Jenkins, G.M. (1976). Time series analysis: Forecasting and control, Holden Day, San Francisco.

[7] Box, G.E.P. \& Jenkins, G.M. (1970). Statistical Models for Forecasting and Control, Holden Day, San Francisco.

[8] Brigo, D., Pede, N. \& Petrelli, A. (2018). "Multi-currency credit default swaps quanto effects and FX devaluation jumps", Cornell University, 2.

[9] Chatfield, C. (1996). "Model uncertainty and forecast accuracy", Journal of Forecasting, 15, 495508.

[10] Cole, H. L. \& Kehoe, P. J. (1998). "Models of sovereign debt: Partial versus general reputations", International Economic Review, 39, 1, 55-70.

[11] Farooqi, A. (2014). "ARIMA model building and forecasting on Imports and Exports of Pakistan:, Pakistan Journal of Statistics and Operation Research.

[12] Gujarati, D. N. (2004). Basic Econometrics (4 ${ }^{\text {th }}$ ed.). Mc-Graw Hill.

[13] Kothari, R. C. (2004). Research methodology: Methods and techniques, $2^{\text {nd }}$ ed., New Age International.

[14] Mcleod, A. L. \& Hipel, K. W. (1994). "Time series modelling of water resources and environmental systems", Amsterdam, Elsevier.

[15] Mustafa, A., Ahmad, M. H \& Ismail, N (2017). "Modeling and forecasting US Dollar/Malaysian Ringgit Exchange rate", Reports on Economics and Finance, 3 (1): 1-13.

[16] Ngan, T. M. U (2016). "Forecasting foreign exchange rate by using ARIMA model: a case of VND/USD exchange rate", Research Journal of Finance and Accounting, 7 (12): 38 - 44.

[17] Nyoni, T. (2018). "Modeling and Forecasting Naira / USD Exchange Rate In Nigeria: a Box -Jenkins ARIMA approach", MPRA paper, 88622

[18] Piadhan, P. Nayak, B. \& Dhal, S. K. (2016). "Time Series Data Prediction of Natural Gas Consumption Using Arima Model", International Journal of Information Technology.

[19] Sreenivasan, M. \& Sumathi, K. (1998). "Innovation algorithm in ARMA process", Korean Journal of Computational \& Applied Mathematics, 5, 2, 331- 340.

[20] Varenius, M. (2017). "Real currency exchange rate prediction: A time series analysis, Bachelor Thesis", Stockholm University. http://www.math.su.se

[21] Waeto, S. Churkhan, K. \& Intarasit, A. (2017). "Forecasting Time Series Movement Direction with Hybrid Methodology", Journal of Probability and Statistics, 3174305.

[22] Yildıran, C. U. \& Fettahoğlu, A. (2017). "Forecasting USDTRY rate by ARIMA method", Cogent Economics \& Finance, 5, 1.

[23] Zhang, G. P. (2007). "A neural network ensemble method with jittered training data for time series forecasting", Information Sciences, 177. 5329-5346.

[24] Zhang, G. P. (2003). "Time series forecasting using a hybrid ARIMA and neural network

[25] Model”, Neurocomputing, 50, 159-175 